\title{
Technological advances in electrochemical biosensors for the detection of disease biomarkers
}

\author{
Jae Hyun Kim ${ }^{1}$. Young Joon Suh ${ }^{1}$. Dongsung Park ${ }^{1,2} \cdot$ Hyoju Yim $^{1} \cdot$ Hongrae Kim ${ }^{1,2} \cdot$ Hye Jin Kim ${ }^{1}$ Dae Sung Yoon ${ }^{2}$. \\ Kyo Seon Hwang ${ }^{1}$ (1)
}

Received: 22 June 2021 / Revised: 13 August 2021 / Accepted: 20 August 2021 / Published online: 27 August 2021

(c) Korean Society of Medical and Biological Engineering 2021

\begin{abstract}
With an increasing focus on health in contemporary society, interest in the diagnosis, treatment, and prevention of diseases has grown rapidly. Accordingly, the demand for biosensors for the early diagnosis of disease is increasing. However, the measurement range of existing electrochemical sensors is relatively high, which is not suitable for early disease diagnosis, requiring the detection of small amounts of biocomponents. Various attempts have been made to overcome this and amplify the signal, including binding with various labeling molecules, such as DNA, enzymes, nanoparticles, and carbon materials. Efforts are also being made to increase the sensitivity of electrochemical sensors, and the combination of nanomaterials, materials, and biotechnology offers the potential to increase sensitivity in a variety of ways. Recent studies suggest that electrochemical sensors can be a powerful tool in providing comprehensive insights into the targeting and detection of disease-associated biomarkers. Significant advances in nanomaterial and biomolecule approaches for improved sensitivity have resulted in the development of electrochemical biosensors capable of detecting multiple biomarkers in real time in clinically relevant samples. In this review, we have discussed the recent studies on electrochemical sensors for detection of diseases such as diabetes, degenerative diseases, and cancer. Further, we have highlighted new technologies to improve sensitivity using various materials, including DNA, enzymes, nanoparticles, and carbon materials.
\end{abstract}

Keywords Electrochemical biosensors $\cdot$ Disease diagnosis $\cdot$ Early diagnosis $\cdot$ Nanomaterials $\cdot$ Biomarkers

\section{Introduction}

Human life has been enriched by the continuous development of science, technology, and industry. However, as the longevity of the human population increases, associated health problems and diseases present a great challenge in the modern society [1]. Biologically, human diseases are accompanied by the secretion of antibodies, hormones, or proteins in body fluids, such as blood, which may appear high or low depending on the disease. These can act as biomarkers, whose single molecules or patterns of molecules derived

Kyo Seon Hwang

k.hwang@khu.ac.kr

1 Department of Clinical Pharmacology and Therapeutics, College of Medicine, Kyung Hee University,

Kyungheedae-ro 26, Dongdaemun-gu, Seoul 02447, Republic of Korea

2 School of Biomedical Engineering, Korea University, Seoul 02841, Republic of Korea from DNA, RNA, metabolites, proteins, and protein fragments are potential indicators of disease. Biomarkers range from low-molecular substances, such as blood glucose, to high-molecular substances, such as proteins or specific nucleic acids, and have evolved along with the development of biochemistry [2]. For example, blood glucose, involved in the diagnosis of diabetes, is the oldest and most widely known biomarker used for both medical diagnosis and new drug development. Recently, biomarkers have been applied for the early diagnosis, investigation of drug response, and evaluating therapeutic effects of several incurable diseases, including cancer, diabetes, AIDS, avian flu, infectious diseases, cardiovascular disease, stroke, and neurodegenerative diseases. The core of the development of biosensors for disease diagnosis relies on the discovery of reliable biomarkers and technology related to the detection method with high sensitivity and selectivity, which is necessary for early diagnosis [3].

The early diagnosis of disease can greatly help to reduce the costs of treatment associated with later stages 
of disease. Although diagnostic devices are already widely used in clinical practice, they still have many limitations. For example, many diagnostic devices are slow to respond and cost the healthcare industry billions of dollars each year [4]. A disease diagnosis sensor that can be used clinically should not only have a high reliability, sensitivity, and reproducibility, but also be economical and accessible, allowing as many users as possible to access it. Detection using biosensors involves adding patient's blood or bodily fluids (e.g. urine, saliva, and tears) on a substrate, then, the target material (biomarker) in the body fluid reacts with a reactant (bioreceptor) fixed on the sensor, and the presence or absence of disease is determined by the specific signal change that appears. The quantification of biological and biochemical processes is very important for medical and biological applications [5]. Biosensors that use electrochemistry are extremely useful due to the fact that they convert biological samples into an electrical signal that can easily process information. Electrochemical signalbased biosensor technology has many advantages, including convenience, rapid detection, relatively low production costs, the miniaturization and portability of the diagnostic system, and the ability of using only a small amount of sample to detect and analyze biomaterials. It is widely used in a variety of fields, such as the identification of toxic substances, the diagnosis of disease, and environmental and food monitoring [6].

Electrochemical sensors have gained attention in recent decades due to their sensitivity, faster analysis, and costeffectiveness. The sensitivity of these sensors is considered key for precision testing in early disease diagnosis, allowing for the detection of a low concentrations of biocomponents. However, the measurement concentration range of the electrochemical sensor is relatively high, making it unsuitable for early diagnosis since most early diagnostic biomarkers are present at very low concentrations. Therefore, new electrochemical sensor technologies for detecting biomarkers present in small concentrations are being developed [7]. Recent trends have shown that electrochemical sensors can be very powerful in providing comprehensive insights into the targeting and detection of disease-associated biomarkers. With the need of detection with a continuous response corresponding to the dynamic concentration variation of the biomarker in biofluid, wearable biosensors have received significant attention due to their potential to provide continuous real-time physiological information through dynamic noninvasive measurements of biochemical markers in biofluids. From glucose monitoring to managing Parkinson's disease, wearable sensors have developed along with the advance of electrochemical biosensors. This review paper introduces important disease diagnosis results, applications, issues, and advanced technologies, including a wearable sensor in the field of electrochemical biosensors, and examines the potential application of advanced biosensors in the future [8].

The research results are summarized and categorized in terms of biomarkers for diseases including diabetes mellitus, neurodegenerative disease, cancer, and coronavirus disease (COVID-19). Figure 1a-d shows the limits of the detection (LOD) trend studied for the last 10 years by dividing the electrochemical sensor into three major diseases: diabetes, neurodegenerative disease, and cancer. From 2012 to now, a low LOD of the sensor is required for the diagnosis of glucose, neurodegenerative diseases, and cancer. The importance of low LOD is not limited to the above diseases, but also to various biomarker such as interleukins and cytokines, which are related to inflammation, which can be the root of all diseases (Fig. 1e). These research results show the need for research on electrochemical sensors with low LOD in order to measure various novel biomarkers present at low concentrations in body fluids, and we reviewed technologies that can increase LOD. Over the past 20 years, the above research has been continuing and has recently 10 years received tremendous attention. Studies on the relationship between neurodegenerative diseases and neuroinflammation are also interested. Many papers used in Fig. 1a-d are listed in Table 1 in the order of sensor target, diseases name, sensor LOD, publication year, and references number. As described above, a technique for improving the detection performance of an electrochemical biosensor to obtain a low LOD, which has been increasingly demanded over the past 20 years, is introduced. Techniques for improving the detection performance of the electrochemical biosensor include the introduction of DNA, enzymes, nanoparticles, and carbon materials into the electrochemical sensor. This review aims to provide meaningful data to researchers in the field of electrochemical sensors by exploring these performance enhancing technologies.

\section{Electrochemical sensors}

The most commonly used biosensor for analysis is the electrochemical sensor. This type of sensor has many advantages for use in the detection of biomaterials, measuring the electrochemical properties that appear depending on the characteristics of the target material that selectively react with the bioreceptor. This facilitates sample preprocessing, enabling the detection of a small amount of target material, even in complex samples. It is often used in combination with antigen-antibody reactions or nucleic acid interactions to increase the selectivity and sensitivity of the target substance [9]. Electrochemical sensors have a simple analysis method and excellent performance with a low manufacturing cost. Moreover, the fact that they can be miniaturized is a significant advantage. Typically, 


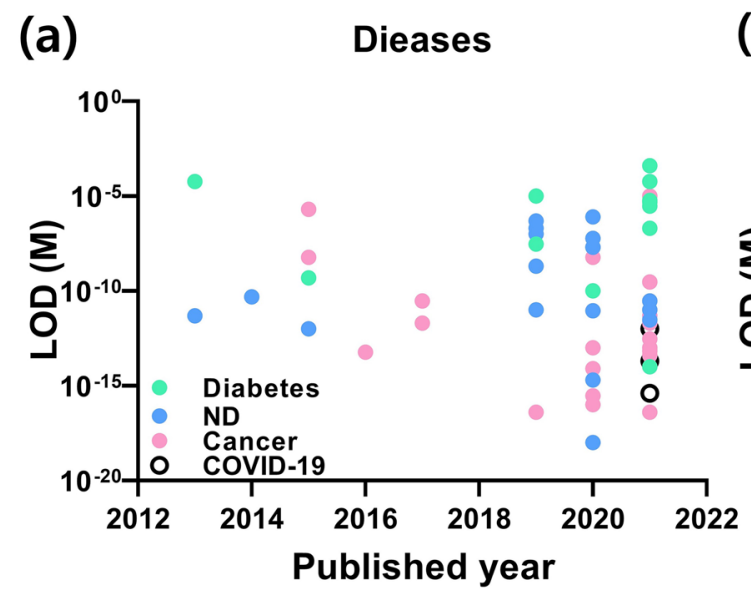

(c)

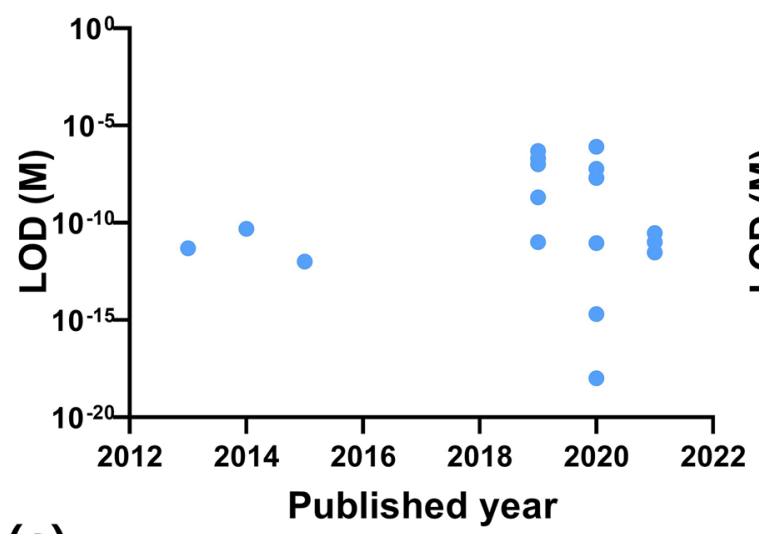

(e)

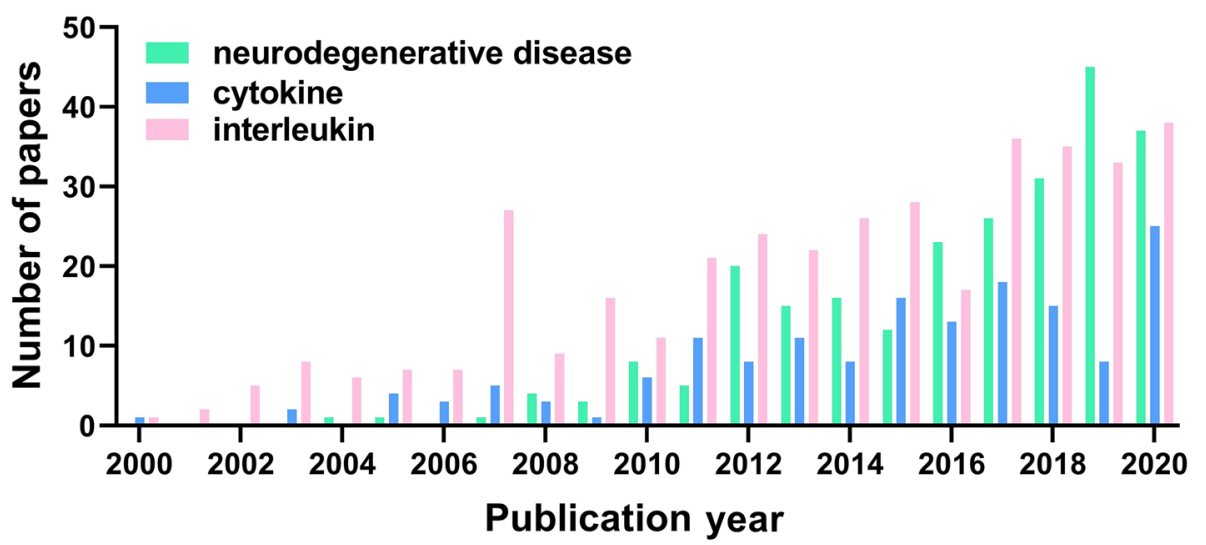

(b)

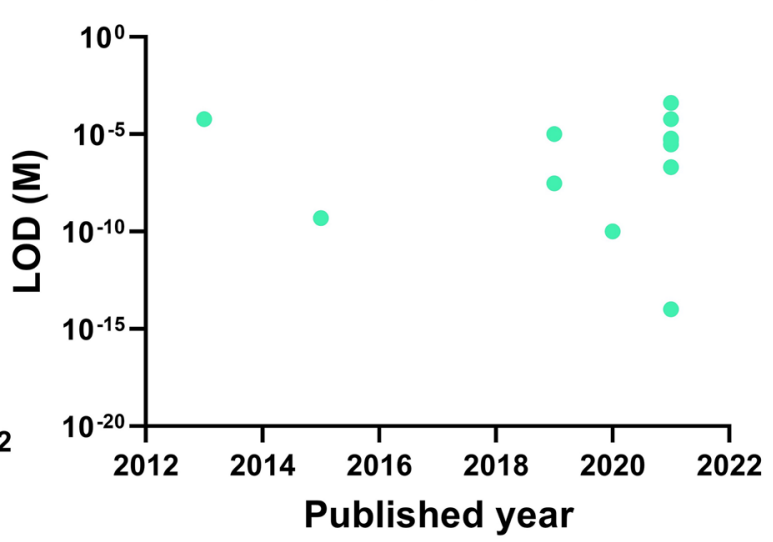

(d)

Cancer

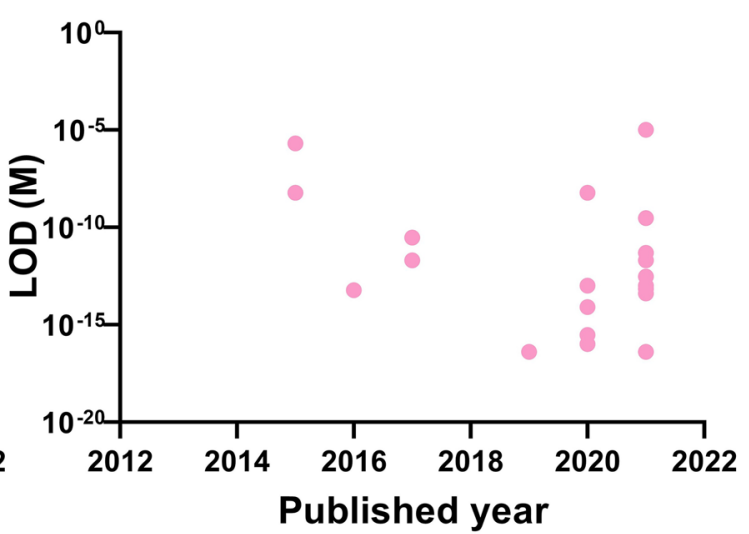

Fig. 1 a shows the limits of the detection (LOD) trend studied for the last 10 years by dividing the electrochemical sensor into three major diseases: $\mathbf{b}$ diabetes, $\mathbf{c}$ neurodegenerative disease, and $\mathbf{d}$ cancer. Representative of 56 data of this review in the field of electrochemical

electrochemical sensors are used as signal transducers. In general, an electrochemical sensor can be classified into an impedance sensor, a current sensor, and a voltage sensor according to a transducer used. [10]. Figure 2 explains analytical principle and three kinds of method of electrochemical biosensors. biosensors over the disease detection. The number of the published papers on neurodegenerative diseases, interleukins and cytokines according to Chemical Abstracts Service (CAS) data e

Impedance has electrical properties that impede current flow. This change depends on the binding between the bioreceptor immobilized on the conductive substrate and the analyte. This technology enables the quantitative and qualitative analysis of a target material by measuring it as an electrical signal through a spectrometer. Impedance-based 
Table 1 The LOD of the electrochemical sensor associated with diabetes mellitus, neurodegenerative disease, and cancer in past decade

\begin{tabular}{|c|c|c|c|c|}
\hline Target & Disease & LOD & Year & References \\
\hline $\mathrm{HbA1C}$ & Diabetes Mellitus & $58 \mu \mathrm{M}$ & 2013 & {$[23]$} \\
\hline Adiponectin & Diabetes Mellitus & $483 \mathrm{pM}$ & 2015 & [20] \\
\hline Glucose & Diabetes Mellitus & $0.03 \mu \mathrm{M}$ & 2019 & [130] \\
\hline $\mathrm{HbA1C}$ & Diabetes Mellitus & $10 \mathrm{nM}$ & 2019 & {$[24]$} \\
\hline Urea & Diabetes Mellitus & $0.14 \mathrm{nM}$ & 2020 & [116] \\
\hline Glucose & Diabetes Mellitus & $6.3 \mu \mathrm{M}$ & 2021 & [19] \\
\hline Lactate & Diabetes Mellitus & $0.41 \mathrm{mM}$ & 2021 & {$[108]$} \\
\hline Glucose & Diabetes Mellitus & $0.057 \mathrm{mM}$ & 2021 & [108] \\
\hline Glucose & Diabetes Mellitus & $5.347 \mu \mathrm{M}$ & 2021 & [104] \\
\hline Glucose & Diabetes Mellitus & $3.35 \mu \mathrm{M}$ & 2021 & [105] \\
\hline Glucose & Diabetes Mellitus & $0.159 \mu \mathrm{M}$ & 2021 & [114] \\
\hline Thrombin & Diabetes Mellitus & $12.77 \mathrm{fM}$ & 2021 & [105] \\
\hline Anti-MBP & Multiple Sclerosis & $4.630 \mathrm{pM}$ & 2013 & {$[47]$} \\
\hline Anti-MBP & Multiple Sclerosis & $4.530 \mathrm{pM}$ & 2013 & [47] \\
\hline$\beta$-Amyloid & Alzheimer's Disease & $50 \mathrm{pM}$ & 2014 & {$[31]$} \\
\hline$\alpha$-Synuclein & Parkinson's Disease & $1.2 \mathrm{pM}$ & 2015 & [38] \\
\hline Glutamate & Alzheimer's Disease, Parkinson's Disease & $0.5 \mu \mathrm{M}$ & 2019 & [119] \\
\hline Glutamate & Alzheimer's Disease, Parkinson's Disease & $0.2 \mu \mathrm{M}$ & 2019 & [119] \\
\hline $\mathrm{H}_{2} \mathrm{O}_{2}$ & Neurodegenerative Disease & $0.1 \mu \mathrm{M}$ & 2019 & [43] \\
\hline Dopamine & Parkinson's Disease & $2.0 \mathrm{nM}$ & 2019 & {$[41]$} \\
\hline miRNA-146a & Alzheimer's Disease & $10 \mathrm{pM}$ & 2019 & [97] \\
\hline Dopamine & $\begin{array}{l}\text { Alzheimer's Disease, Parkinson's Disease, } \\
\text { Schizophrenia }\end{array}$ & $0.76 \mu \mathrm{M}$ & 2020 & [123] \\
\hline $\mathrm{Fe}^{2+}$ & Alzheimer's Disease & $60 \mathrm{nM}$ & 2020 & {$[36]$} \\
\hline $\mathrm{H}_{2} \mathrm{O}_{2}$ & Alzheimer's Disease, Parkinson's Disease & $0.02 \mu \mathrm{M}$ & 2020 & {$[44]$} \\
\hline Dopamine & Alzheimer's Disease & $8.75 \mathrm{pM}$ & 2020 & [128] \\
\hline t-Tau & Alzheimer's Disease & $1.59 \mathrm{fM}$ & 2020 & {$[35]$} \\
\hline Amyloid $\beta$ Oligomer & Alzheimer's Disease & $1.0 \mathrm{aM}$ & 2020 & {$[32]$} \\
\hline $\mathrm{L}-\mathrm{A} \beta_{40} \mathrm{O}$ & Alzheimer's Disease & $26 \mathrm{pM}$ & 2021 & {$[28]$} \\
\hline Dopamine & Parkinson's Disease & $10 \mathrm{pM}$ & 2021 & {$[40]$} \\
\hline $\mathrm{L}-\mathrm{A} \beta_{42} \mathrm{O}$ & Alzheimer's Disease & $3.0 \mathrm{pM}$ & 2021 & {$[28]$} \\
\hline$\alpha$-fetoprotein & Liver Cancer & $3.57 \mathrm{pM}$ & 2009 & {$[68]$} \\
\hline CA72-4 & Cancer & $2.083 \mu \mathrm{M}$ & 2015 & [74] \\
\hline CA72-4 & Cancer & $6.25 \mathrm{nM}$ & 2015 & [73] \\
\hline CYFRA21-1 & Lung Cancer & $57.5 \mathrm{fM}$ & 2016 & [59] \\
\hline Prostate-specific antigen & Prostate Cancer & $29.4 \mathrm{pM}$ & 2017 & {$[71]$} \\
\hline Vascular endothelial growth factor & Prostate Cancer & $1.849 \mathrm{pM}$ & 2017 & [71] \\
\hline miRNA-21 & Cancer & $0.04 \mathrm{fM}$ & 2019 & {$[98]$} \\
\hline miRNA-492 & Pancreatic ductal adenocarcinoma & $6.0 \mathrm{nM}$ & 2020 & {$[92]$} \\
\hline p53 protein & Tumor & $0.1 \mathrm{pM}$ & 2020 & [117] \\
\hline miRNA-141 & Prostate Cancer & $7.78 \mathrm{fM}$ & 2020 & {$[95]$} \\
\hline miRNA-21 & Cancer & $0.29 \mathrm{fM}$ & 2020 & [99] \\
\hline Neuron specific enolase & Small Cell Lung Cancer & $0.135 \mathrm{fM}$ & 2020 & {$[57]$} \\
\hline miRNA-9-2 & Cancer & $100 \mathrm{aM}$ & 2020 & [93] \\
\hline let-7a & Cancer & $0.25 \mathrm{nM}$ & 2021 & {$[100]$} \\
\hline Cytokeratin 19 fragment $21-1$ & Lung Cancer & $4.5 \mathrm{pM}$ & 2021 & {$[60]$} \\
\hline Carcinoembryonic antigen & Lung Cancer & $1.55 \mathrm{pM}$ & 2021 & {$[60]$} \\
\hline miRNA-196b & Pancreatic Cancer & $0.26 \mathrm{pM}$ & 2021 & [94] \\
\hline ctDNA & Cancer & $0.13 \mathrm{pM}$ & 2021 & {$[12]$} \\
\hline$\alpha$-fetoprotein & Liver Cancer & $71.4 \mathrm{fm}$ & 2021 & [69] \\
\hline
\end{tabular}


Table 1 (continued)

\begin{tabular}{|c|c|c|c|c|}
\hline Target & Disease & LOD & Year & References \\
\hline $\begin{array}{l}\text { Metastasis-associated lung adenocarcinoma } \\
\text { transcript } 1\end{array}$ & Non-Small Cell Lung Cancer & $42.8 \mathrm{fM}$ & 2021 & {$[15]$} \\
\hline Human epidermal growth factor receptor 2 & Breast Cancer & $42.34 \mathrm{fM}$ & 2021 & {$[55]$} \\
\hline Circulating tumor DNA & Cancer & $36 \mathrm{aM}$ & 2021 & [102] \\
\hline L-Fucose & Liver Cancer & $13.6 \mu \mathrm{M}$ & 2021 & [106] \\
\hline
\end{tabular}

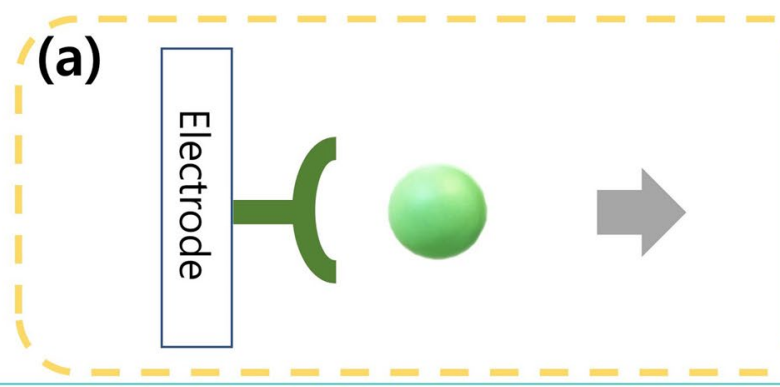

\section{(b) (a) Impedance}

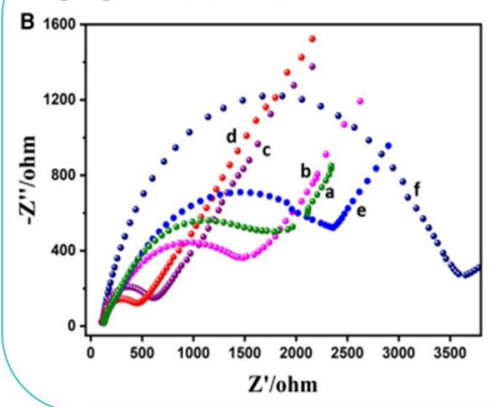

(b) Amperometry

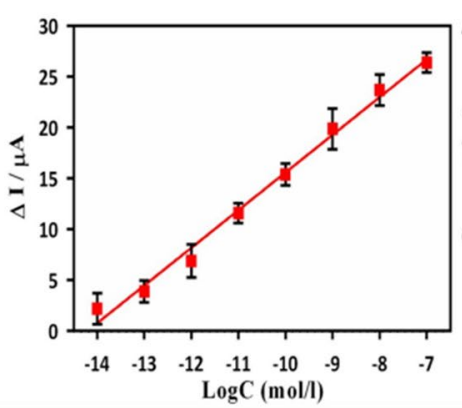

(c) Voltammetry

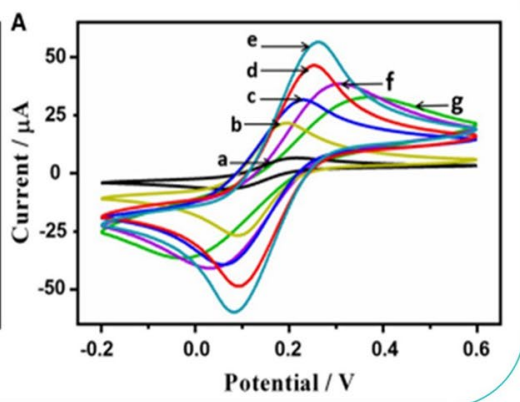

Fig. 2 Schematic illustration of basic principle (a) and measurement methods (b) of electrochemical sensors

electrochemical biosensors have the advantages of being fast, sensitive, and the fact that they can be miniaturized. However, they also have the disadvantage of reducing the degree of power and causing current flow obstruction [11]. To overcome this and amplify the signal, various attempts have been made, such as binding with various labeling molecules such as DNA, enzymes, nanoparticles, and carbon materials [12-15].

Current- and voltage-based sensors measure the oxidation-reduction reaction signal of the analyte generated at the working electrode when a constant potential difference is applied to the reference and working electrodes. The measured current is proportional to the concentration of the analyte and has a high sensitivity. However, current- and voltage-based sensors also have a disadvantage in that only substances with electrochemical activity can be detected. However, current- and voltage-based biosensors are the most widely studied because they can be miniaturized and can detect target substances with high sensitivity in a short amount of time with a low cost of detection and development. As a result, these sensors are actively being used in the field of disease detection [16].

\section{Electrochemical sensors for the detection of disease}

Electrochemical sensors are widely used for the diagnosis of various diseases. In this review, we focused on studies dealing with diagnosis of diabetes, neurodegenerative disease, cancer, and COVID-19 infection using electrochemical sensors. Biomarkers are diagnostic indicators that play an important role in assessing the risk or presence of a disease. The biomarkers shown in Table 2 are those considered in this review. 
Table 2 Biomarkers of various diseases

\begin{tabular}{|c|c|c|c|}
\hline Biomarker & Type & Disease & References \\
\hline Glucose & Carbohydrate & Diabetes & [17] \\
\hline Adiponectin & Protein & Diabetes & {$[22]$} \\
\hline Glycated hemoglobin A1c & Hemoglobin & Diabetes & {$[23]$} \\
\hline Amyloid $\beta$ & Peptide & $\mathrm{AD}$ & {$[27]$} \\
\hline Tau & Protein & $\mathrm{AD}$ & {$[33]$} \\
\hline $\mathrm{Fe}^{2+}$ & Ion & $\mathrm{AD}$ & {$[36]$} \\
\hline$\alpha$-synuclein & Protein & PD & {$[37]$} \\
\hline Dopamine & Neurotransmitter & $\mathrm{PD}$ & [39] \\
\hline $\mathrm{H}_{2} \mathrm{O}_{2}$ & Reactive oxygen species & $\mathrm{AD}, \mathrm{PD}$ & [42] \\
\hline Anti-myelin basic protein & Protein & MS & [46] \\
\hline Human mucin-1 & Protein & Breast cancer & {$[51]$} \\
\hline Carcinoembryonic antigen & Antigen & Cancer & {$[52]$} \\
\hline Human epidermal growth factor receptor 2 & Gene & Breast cancer & {$[54]$} \\
\hline Neuron-specific enolase & Enzyme & Small cell lung cancer & {$[56]$} \\
\hline Cytokeratin 19 fragment $21-1$ & Antigen & Non-small cell lung cancer & {$[58]$} \\
\hline Murine colon tumor 26 & Cell & Colorectal cancer & {$[61]$} \\
\hline$\alpha$-fetoprotein & Protein & Liver cancer & {$[66]$} \\
\hline Prostate-specific antigen & Antigen & Prostate cancer & {$[70]$} \\
\hline Vascular endothelial growth factor & Gene & Cancer & [71] \\
\hline Cancer antigen $72-4$ & Antigen & Gastric cancer & {$[72]$} \\
\hline Leukemia cancer cells & Cell & Acute lymphoblastic leukemia & {$[73]$} \\
\hline miRNA-492 & miRNA & Pancreatic cancer & [92] \\
\hline miRNA9-2 & miRNA & Carcinoma & [93] \\
\hline miRNA-196b & miRNA & Pancreatic cancer & [94] \\
\hline miRNA-141 & miRNA & Prostate cancer & [95] \\
\hline miRNA-21 & miRNA & Cancer & [98] \\
\hline miRNA let-7a & miRNA & Cancer & {$[100]$} \\
\hline Circulating tumor DNA & DNA & Cancer & {$[101]$} \\
\hline Procalcitonin & Protein & Septicemia, pyemia & [112] \\
\hline Glutamate excitotoxicity & Protein & $\mathrm{AD}, \mathrm{PD}$ & [119] \\
\hline
\end{tabular}

AD (Alzheimer's disease); PD (Parkinson's disease); MS (multiple sclerosis)

\subsection{Diabetes mellitus}

Diabetes mellitus (DM) is one of the most common chronic metabolic diseases and a major global health issue, with the prevalence of diabetes continuing to increase worldwide [17]. Since Clark and Lyons first proposed the concept of biosensors in 1962, many efforts have been made to develop devices for the diagnosis of diabetes [18]. The measurement of the blood glucose concentration is a major diagnostic criterion for diabetes. Electrochemical glucose biosensors are based on the detection of hydrogen peroxide. However, the current measurement of hydrogen peroxide requires a high potential for a high selectivity [17]. This can be overcome through the use of artificial parameters to shuttle electrons between the center and the surface of the adenine dinucleotide. A timeline summarizing the major advances in electrochemical glucose sensing over the past decade is shown in Fig. 3a [18]. In recent years, 2D Group 14 graphene analogs have attracted much interest owing to their simple synthesis procedures and numerous attractive properties. Pumera et al. proposed a glucose biosensor by depositing Group 14 graphane analogs onto glassy carbon electrodes, followed by Glucose Oxidase (GOx) and glutaraldehyde. The fabricated biosensing platform delivered excellent analytical performance, displaying good linearity over numerous magnitudes of glucose concentrations and a low limit of detection (LOD) of $6.3 \times 10^{-6} \mathrm{~m}$. As shown in Fig. 3b, c, the fabricated glucose biosensor was used to determine glucose in human serum, demonstrating the viability of the sensing platform for real sample analysis [19]. Another biomarker for diabetes is adiponectin, which is an abundant 244-amino acid plasma protein that is primarily produced in adipose tissue and is involved in the metabolism of lipids and glucose, particularly in the regulation of insulin 
(a)

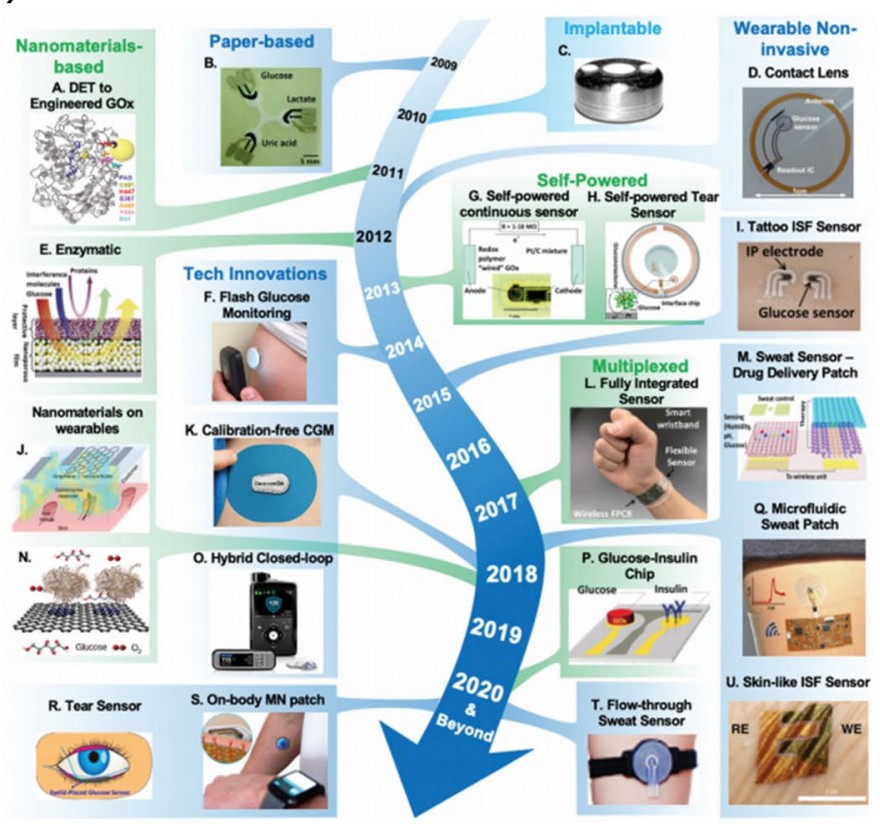

(b)

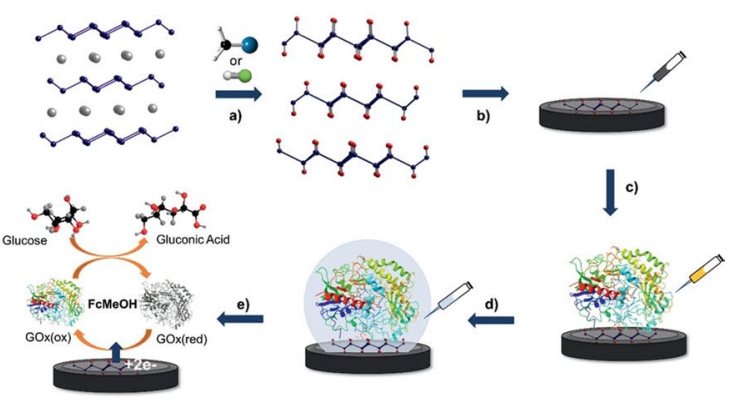

(c)
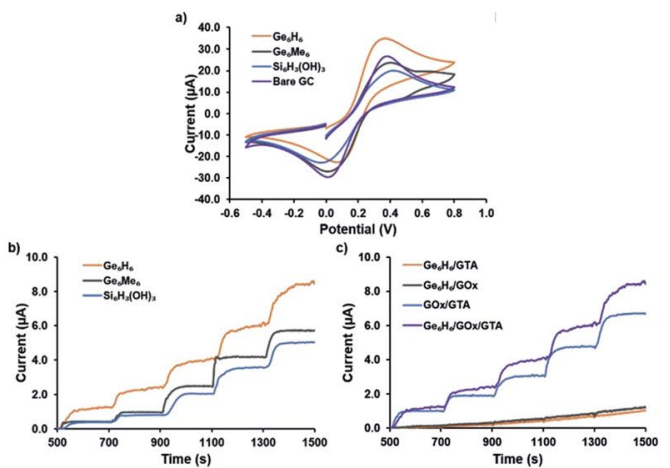

Fig. 3 a Representative of key advances in the field of electrochemical glucose biosensors over the past decade. Reproduced with permission from ref. [18]. Copyright (2020) ACS. b Schematic illustration depicting the deintercalation of $\mathrm{CaGe} 2$ or $\mathrm{CaSi} 2 \mathrm{Zintl}$ phases. c
Cyclic voltammograms, Chronoamperometry curves of the glucose oxidase-based electrochemical glucose biosensor and Chronoamperometry curves of the various electrode configurations. $\mathbf{b}$ and $\mathbf{c}$ reproduced with permission from ref. [19]. Copyright (2021) Wiley resistance. Yáñez-Sedeño et al. developed an immunosensor using screen-printed carbon electrodes altered with functionalized double-walled carbon nanotubes. Under the selected conditions, a calibration plot for adiponectin was constructed showing a range of linearity extending between 0.05 and $10.0 \mu \mathrm{g} / \mathrm{mL}$, which is adequate for the determination of the cytokine in clinical samples. A detection limit of $14.5 \mathrm{ng} / \mathrm{mL}$ was achieved. The prepared immunosensor exhibited good reproducibility for adiponectin measurements, excellent storage stability and selectivity, and a much shorter assay time than the currently available ELISA kits [20].

Glycated hemoglobin Alc (HbA1c) is a stable glycated hemoglobin derivative generated by the non-enzymatic reaction of the $\mathrm{N}$-terminal valine residue of the $\mathrm{Hb} \beta$-chains with plasma glucose [21]. The HbA1c level, defined as the ratio between the $\mathrm{HbA} 1 \mathrm{c}$ concentration and total $\mathrm{Hb}$ concentration, reflects the ambient glycemic level over the past 2-3 months [22]. Shim et al. used a hybrid structure composed of a poly terthiophene benzoic acid as a conductive polymer, and gold nanoparticles were used for $\mathrm{HbA} 1 \mathrm{C}$ amperometric biosensor construction. Using this simple platform, the proposed biosensor achieved a detection limit of $0.052 \pm 0.02 \%$ and a linear dynamic range of $0.1-1.5 \%$ [23]. Mi et al. developed gold nano-flower-modified disposable 16-channel screen-printed carbon electrodes using the catalytic property of $\mathrm{HbA1c}$, which was confirmed using voltammetry. The proposed biosensor had a large dynamic range of $5-1000 \mu \mathrm{g} / \mathrm{mL}$ and $2-20 \%$, as well as good detection specificity and relative stability [24]. Glucose measurement biosensors analyze glucose levels primarily through the blood. However, this method is inconvenient and may reduce patient compliance. To overcome this, several wearable glucose-sensing devices for continuous monitoring have been developed. More details are provided later in the review.

\subsection{Neurodegenerative disease}

Neurodegenerative disease (ND) is a rapidly spreading age-dependent disorder that poses a major threat to human health [25]. Neurodegenerative diseases include a variety of diseases with different pathological patterns and aspects, such as Alzheimer's disease (AD), Parkinson's disease (PD), and amyotrophic lateral sclerosis (ALS) [26]. Given the late onset of ND symptoms, early diagnosis and prompt treatment of ND are paramount [27]. AD is the most common age-related neurodegenerative disorder, causing progressive cognitive decline and irreversible memory impairment. The major components of senile plaques are aggregates of amyloid $\beta$ peptide (A $\beta$ ), such as oligomers and fibrils. Therefore, $\mathrm{A} \beta$ has been identified as a reliable molecular biomarker for the detection and diagnosis of AD [28]. A $\beta$ contains 39-43 
amino acid residues, and the main subtypes are $A \beta 40$ and $\mathrm{A} \beta 42$ [29]. The degree of cognitive deficit in AD is closely related to the relative levels of low-mass soluble oligomers of $A \beta 40$ and $A \beta 42$ (L-A $\beta 40 O$ and L-A $\beta 42 O$ ) [30]. For example, Shi et al. reported a novel electrochemical biosensor to detect $A \beta$ levels using gelsolin, a secreted protein that binds $A \beta 40$ and $A \beta 42$ monomers with high specificity. Biosensors were fabricated by immobilizing gelsolin on screen-printed carbon electrodes (SPCEs), followed by the binding of thionine (Th) labels linked to gold nanoparticles (AuNPs), which were subsequently used for electrochemical readouts. They also reported that multi-walled carbon nanotubes (MWCNTs) and AuNPs were more effective when used simultaneously as a substrate than either one alone. These results are particularly relevant because the ratio of A $\beta 42 / A \beta 40$ in CSF has been proposed as a reliable predictor of AD progression [31]. Functional conducting polymers are used as electron transport materials, and their functional groups are used to anchor biometric elements. Cho et al. developed a gold dendrite polypyrrole-3-carboxylic acid cellular prion protein (AuD-PPy-3-COOH/PrPC) electrochemical biosensor with a high detection range at the atomic level. There was a proportional relationship with the increase in $\mathrm{A} \beta \mathrm{O}$ concentration from $10-9 \mathrm{nM}$ to $10 \mathrm{nM}$. The sensor can detect $\mathrm{A} \beta \mathrm{O}$ at relatively low concentrations, such as in blood or CSF, in patients with $\mathrm{AD}$ [32].

Another biomarker for $\mathrm{AD}$ is tau protein, which exists in six isoforms with 352 441 amino acid residues [33]. Studies have shown that total tau protein in the blood is an effective biomarker for distinguishing $\mathrm{AD}$ patients from normal individuals and predicting the progression of neurodegeneration in the brain of AD patients [34]. Park et al. reported an artificial electron donor-free bismuth vanadate (BiVO4)-based photoelectrochemical (PEC) analysis to detect tau protein at the femtomolar level. This platform was constructed by incorporating a molybdenum dopant and an iron oxyhydroxide ad-layer into the $\mathrm{BiVO} 4$ photoelectrode and employing a signal amplifier formed by horseradish peroxidase (HRP)-triggered oxidation of 3,3-diaminobenzidine (DAB). The limits of detection and quantitation were determined to be $1.59 \mathrm{fM}$ and $4.11 \mathrm{fM}$ [35]. In addition, the detection of $\mathrm{Fe}^{2+}$ is another way to detect AD. A previous study has demonstrated a close link between the disruption of iron homeostasis and AD. Tian et al. found that extracellular $\mathrm{Fe}^{2+}$ uptake into the cortex and striatum is mediated primarily by circulating adenosine monophosphate (cAMP) via a CREB-associated pathway in the brains of mice with AD. The electrochemical sensor developed based on the $\mathrm{Au}-\mathrm{C} \equiv \mathrm{C}$ bonding surface showed excellent analytical performance for $\mathrm{Fe}^{2+}$ detection in the range of $0.2-120 \mu \mathrm{M}$, including a high affinity, high selectivity, and long-term stability [36]. Figure 4 shows various electrochemical sensors for detecting $\mathrm{AD}$.
PD is a neurodegenerative disorder characterized by motor symptoms, including ataxia, tremors, stiffness, and postural instability. The potential biomarker that has received the most attention is $\alpha$-synuclein, which has been found to aggregate into Lewy bodies in PD patients [37]. Graphene oxide possesses hydroxyl, epoxy, and carboxyl functional groups that can selectively act with appropriate reagents. Davis et al. developed a graphene oxide cysteamine-based electrochemical sensor to detect $\alpha$-synuclein, which reported a LOD of $1.2 \pm 0.3 \mathrm{pM}$, showing a high sensitivity and selectivity [38].

Dopamine (DA), a monoamine neurotransmitter, is involved in a variety of physiological processes, including motor control, learning, and reward signaling. Because PD is characterized by a severe depletion of the dopamine pool in vivo, the ability to measure the concentration of the neurotransmitter dopamine sensitively and selectively could potentially be used for the molecular diagnosis of PD. The ability to physiologically determine DA concentrations can aid in the design of therapeutics and the evaluation of therapeutic efficacy for PD [39]. Wang et al. employed a solidphase microextraction (SPME) technique integrated nano biosensor to trace and quantify dopamine concentration fluctuations in the cytoplasm of single living cells. The SPMEelectrochemical detection system exhibited excellent properties for the detection of $10 \mathrm{pmol} / \mathrm{L}$ dopamine in samples after extraction [40]. Liu et al. developed an electrochemical biosensor based on NiAl layered double hydroxide nanosheets with negatively charged monolayers of graphene layer by layer (NiAl LDH/G LBL), which showed an excellent selectivity and durability, a wide linear range $(0.1-97 \mu \mathrm{M})$, and a low detection limit (2 $\mathrm{nM})$ [41].

Hydrogen peroxide $\left(\mathrm{H}_{2} \mathrm{O}_{2}\right)$ is a reactive oxygen species that plays important physiological roles in brain function and is implicated in $\mathrm{AD}$ and PD. Jiang et al. developed CuS/ RGO composite films for detecting $\mathrm{H}_{2} \mathrm{O}_{2}$ in human serum and urine samples. The CuS/RGO composite films had a sensitivity of $26.5 \mu \mathrm{A} / \mathrm{mM}$ and a rapid response time (less than $2 \mathrm{~s}$ ) [42]. Wang et al. constructed an $\mathrm{RGO} / \mathrm{Au} / \mathrm{Fe} 3 \mathrm{O} 4 /$ Pt-modified glassy carbon electrode to detect $\mathrm{H}_{2} \mathrm{O}_{2}$ in living cells. The $\mathrm{H}_{2} \mathrm{O}_{2}$ sensor shows a low overpotential of $0 \mathrm{~V}$, a low detection limit $(\sim 0.1 \mu \mathrm{M})$, a large linear range $(0.5-11.5 \mathrm{mM})$, and excellent reproducibility [43]. Xu et al. developed a "turn-on" ratiometric electrochemical sensor for detecting $\mathrm{H}_{2} \mathrm{O}_{2}$ from whole blood samples, which showed a good linear range $(0.5-400 \mu \mathrm{M})$ and a low detection limit $(0.02 \mu \mathrm{M})$ [44].

Multiple sclerosis (MS) is a neuroinflammatory and neurodegenerative disease that damages myelin and axons in the central nervous system (CNS) and preferentially affects young adults [45]. Studies have reported that antibodies against myelin basic proteins, such as the autoantibody anti-myelin basic protein (MBP), are present during 


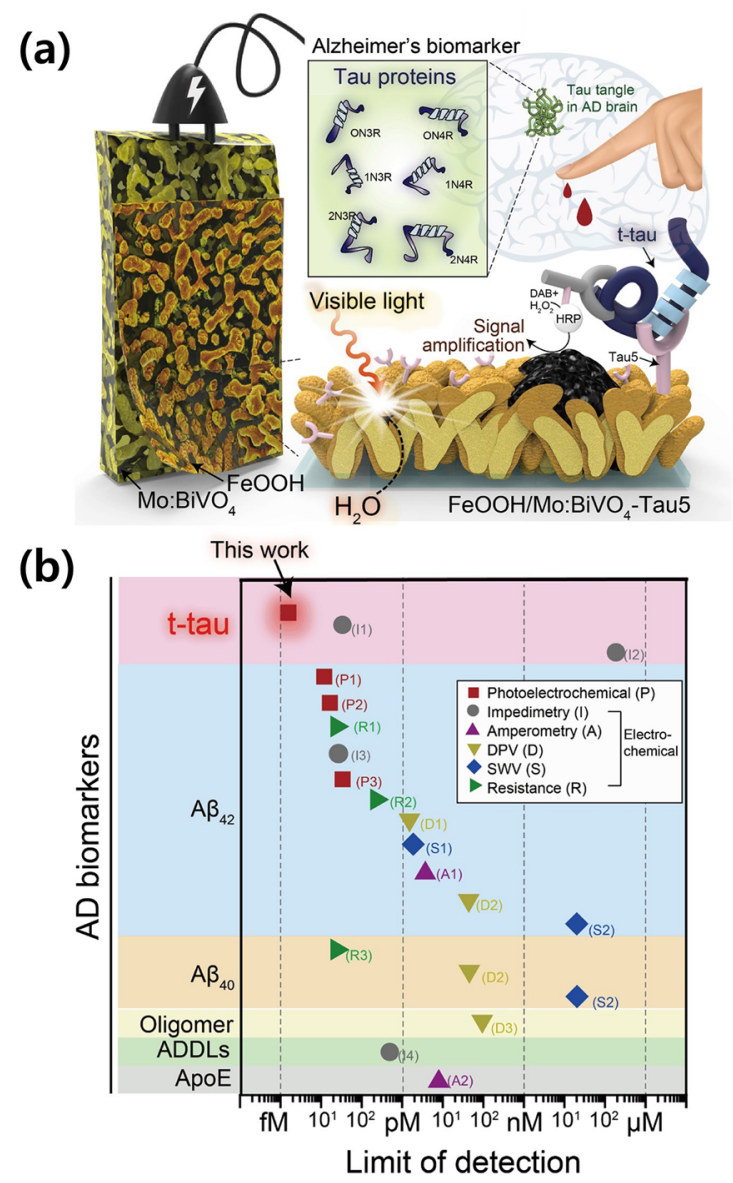

Fig. 4 a Schematic illustration of water oxidation-coupled, $\mathrm{FeOOH} /$ Mo: BiVO4-based photoelectrochemical sensing platform for detecting Alzheimer's tau proteins of femtomolar levels. b Detection limits of $\mathrm{AD}$ biomarker-targeting sensing platforms reported so far. a and b Reproduced with permission from Ref. [35]. Copyright (2020) Elsevier. c Scheme 1. A schematic illustration of the electrochemical detection of $\mathrm{Ab}(1-40 / 1-42)$ by using a gelsolin-Au-Th biocon-

early stages of MS [46]. Emregul et al. developed an electrochemical immunosensor to detect anti-MBP in human CSF and the serum of relapsing-remitting MS patients using a gelatin-TiO2-MBP electrode. Titanium dioxide (TiO2) nanoparticles were used for immunosensor fabrication because of their high surface area and electron transfer rate promoting properties. The immunosensors had wide linear ranges $(0.975-2500 \mathrm{ng} / \mathrm{mL}$ for the gelatin-MBP electron and $0.4875-2500 \mathrm{ng} / \mathrm{mL}$ for the gelatin-TiO2MBP electrode) and low detection limits $(0.1528 \mathrm{ng} / \mathrm{mL}$ for the gelatin-MBP immunosensor and $0.1495 \mathrm{ng} / \mathrm{mL}$ for the gelatin-TiO2-MBP immunosensor). Moreover, the developed immunosensors are less time consuming (58 $\mathrm{s}$ for the gelatin-MBP immunosensor and $46 \mathrm{~s}$ for the gelatin-MBP-TiO2-MBP immunosensor) [47].

d)
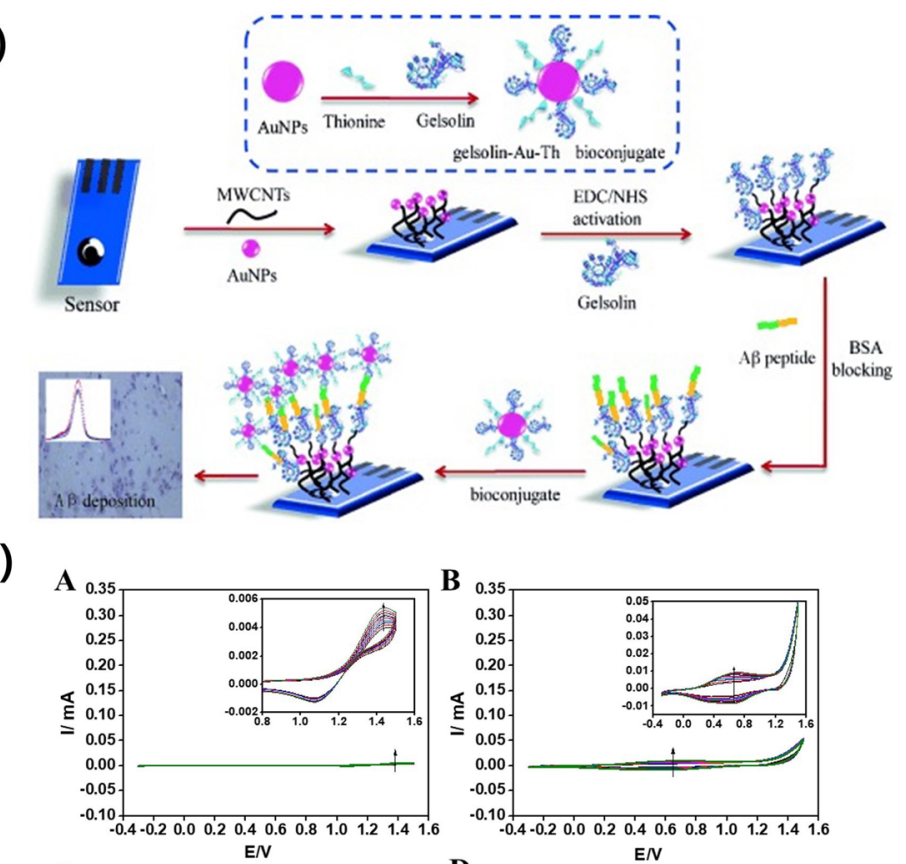

C
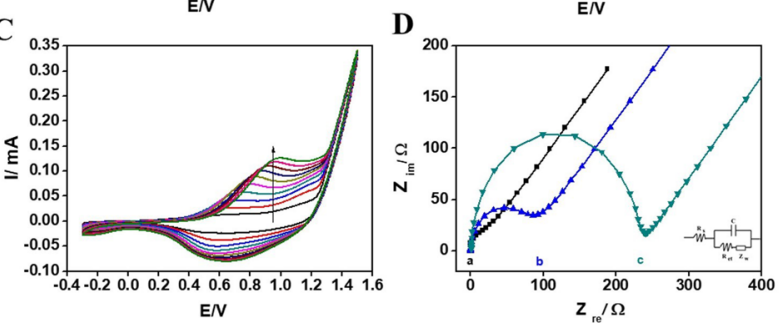

jugate as a probe. Reprinted with permission from Ref. [31]. Copyright (2014) Wiley. d Cyclic voltammetry from anhydrous acetonitrile containing $0.1 \mathrm{M} \mathrm{LiClO}_{4}$ solution and $0.1 \mathrm{M}$ 3-thiophene-3-acetic acid, Pyrrole-2-carboxylic acid, Pyrrole-3-carboxylic acid on gold disc. Nyquist plots of modified electrode. Reproduced with permission from Ref. [32]. Copyright (2020) Elsevier

\subsection{Cancer}

Cancer is one of the deadliest diseases worldwide, with over 10 million new cases every year [48]. Until the late twentieth century, cancer was diagnosed only when symptoms of tumor growth appeared. As a result, in most cases the cancer had already spread at the time of diagnosis, limiting the effectiveness of surgery or radiation therapy. Despite this, symptomatic manifestations remain the main route of diagnosis for all cancers. However, for some types of cancer, tests have been developed to identify changes in tissues indicative of cancer precursors or early stage tumors [49]. The early diagnosis of cancer is important for the successful treatment of this disease. Highly sensitive methods are urgently needed to measure cancer diagnostic markers that 
are present at very low levels in the early stages of disease. Electrochemical biosensors are very useful for providing diagnostic information in a fast, simple, and inexpensive way, making them uniquely qualified to meet the requirements of field cancer screening [4]. Examples of electrochemical sensors detecting cancer are in Fig. 5 with electrochemical characteristics.

As of 2020, female breast cancer surpassed lung cancer as the leading cause of cancer and is the fifth leading cause of cancer-related mortality worldwide [50]. The mucin-1 (MUC1) and carcinoembryonic antigen (CEA) are the most common markers used to monitor metastatic breast cancer. Excessive levels of MUC1 are considered important diagnostic markers of breast cancer, as highly overexpressed MUC1 is frequently found in all-cytoplasmic or periplasmic breast cancers [51]. CEA, one of the first tumor markers used in breast cancer, has limited value in the early detection of cancer [52]. Li et al. developed a new electrochemical assay to select breast cancer cells by simultaneously recognizing two tumor biomarkers, MUC1 and CEA, on the surface of breast cancer cells. The cytosensor can specifically monitor breast cancer cells MCF-7 in a wide range $\left(10^{4}-10^{7}\right.$ cells $/ \mathrm{mL}$ ) with good reproduction and a low detection limit. Compared to detection methods that evaluated only MUC1, the additional detection of CEA could provide more accurate prognostic information, and could help to classify tumors in more detail, thus maximizing the efficacy and minimizing

(a)
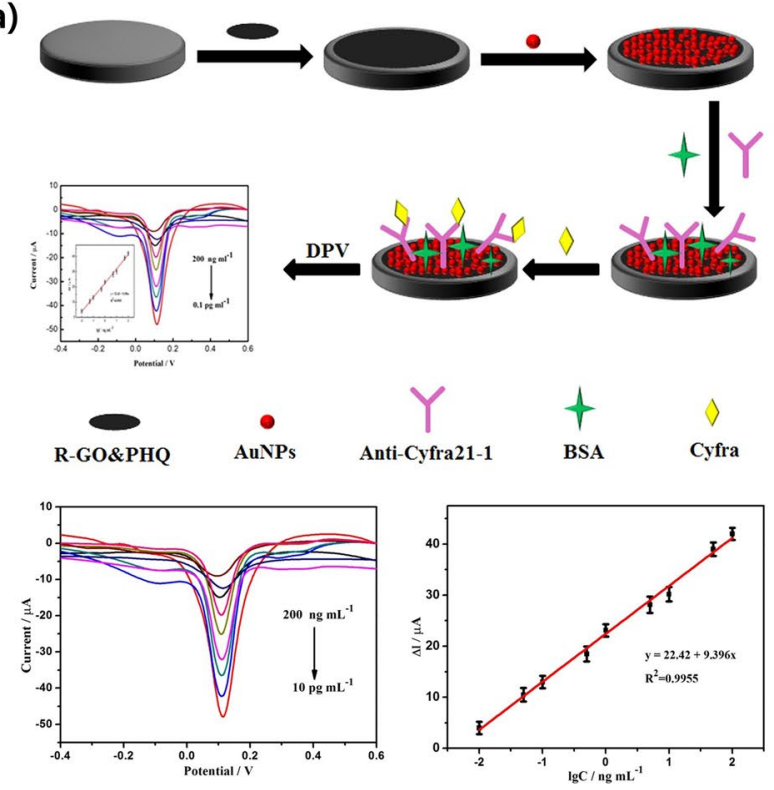

Fig. 5 a Schematic illustration of the fabrication process of the immunosensing interface, DPV responses of electrochemical immunoassay and the calibration plot between the DPV peak current and the logarithm values of CYFRA21-1 concentrations. Reproduced with permission from Ref. [59]. Copyright (2016) Springer. b Sche- the toxicity by planning more appropriate cancer treatment depending on the distinct tumor cell type [53]. Human epidermal growth factor receptor 2 (Her-2) is another crucial biomarker in breast cancer [54]. Salama et al. developed a gold nanostructured modified laser-scribed graphene (LSG)based electrochemical aptasensor for the detection of Her-2 biomarkers. These unique features enabled the development of a low-cost, highly sensitive aptasensor with good reproducibility and a low LOD $(0.008 \mathrm{ng} / \mathrm{mL})$ [55].

Lung cancer is the leading cause of cancer morbidity and mortality in men. It is also the third most common cause of cancer in women, after breast and colorectal cancer, and the second leading cause of death after breast cancer. The incidence and mortality in men are approximately twice as high as in women [50]. Neuron-specific enolase (NSE) is a glycolytic enzyme that is mainly located in the central and peripheral neurons and neuroendocrine tissues. NSE has been reported to be elevated in small cell lung cancer (SCLC). An increased NSE level (> $25 \mathrm{ng} / \mathrm{mL}$ ) was observed in $72 \%$ of patients with SCLC. Currently, NSE serves as an important tumor marker, especially for the diagnosis and treatment of SCLC [56]. Aydin et al. developed an ultrasensitive, specific, and label-free electrochemical immunosensor based on epoxy-substitutedpolypyrrole polymer-modified indium tin oxide. This electrochemical immunosensor had a low LOD of $6.1 \mathrm{fg} / \mathrm{mL}$ with a wide linear detection range $(0.02-7.5 \mathrm{pg} / \mathrm{mL})$ [57].

(b)
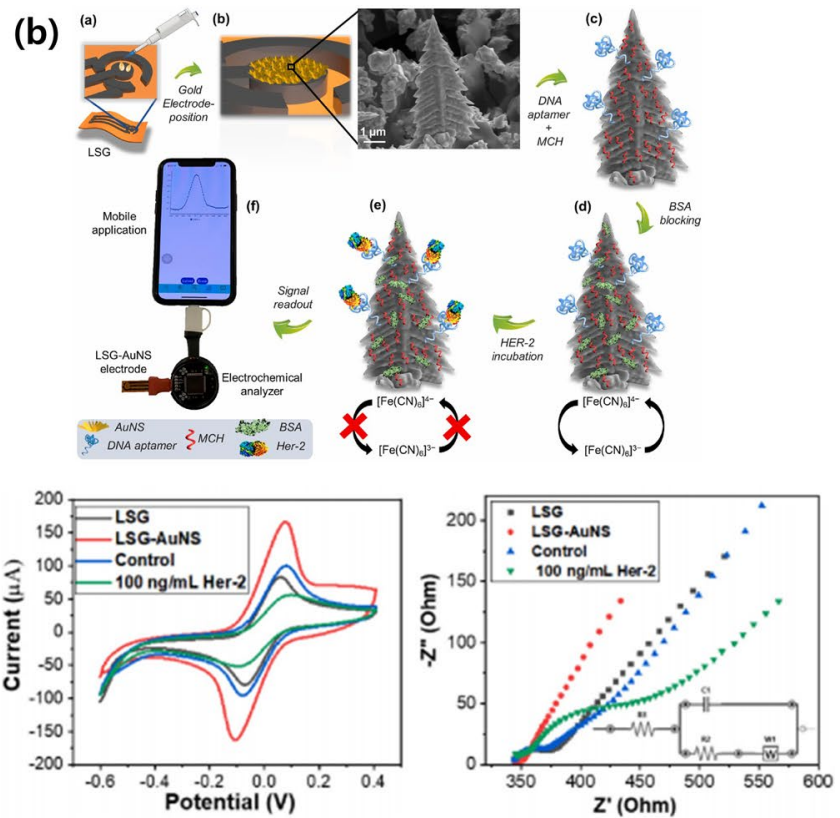

matic illustration of the AuNS modified LSG-based aptasensor. Cyclic voltammograms of bare LSG electrode, Nyquist plots for bare LSG. Reproduced from with permission Ref. [55]. Copyright (2021) Elsevier 
Cytokeratin 19 fragment21-1 (CYFRA 21-1), a 36-kDa fragment of cytokeratin 19, is located in the cytoskeleton of epithelial cells and is the only origin of CYFRA 21-1, which offers a high specificity. CYFRA $21-1$ is currently the most sensitive tumor biomarker for non-small cell lung cancer (NSCLC) and has been demonstrated to be exclusively expressed in lung tissue [58]. Wang et al. proposed an electrochemical immunosensor with a redox-active polyhydroquinone-graphene composite. The reported electrochemical immunosensor showed a wide linear range $(10 \mathrm{pg} / \mathrm{mL}$ to $200 \mathrm{ng} / \mathrm{mL})$ with a detection limit of $2.3 \mathrm{pg} /$ $\mathrm{mL}$ and a good stability and selectivity compared to that of ELISA [59]. Huo et al. developed an electrochemical immunosensor to detect CYFRA21-1 and CEA simultaneously. Its detection linear range extended from $0.5 \mathrm{ng} / \mathrm{mL}$ to $200 \mathrm{ng} / \mathrm{mL}$ with low detection limits (LOD) of $0.18 \mathrm{ng} /$ $\mathrm{mL}$ and $0.31 \mathrm{ng} / \mathrm{mL}$ for CYFRA21-1 and CEA, respectively [60].

Colorectal cancer (CRC) is the third most prevalent tumor and a significant contributor to high mortality. Murine colon tumor 26 (CT26) cells were developed in 1975 by exposing $\mathrm{BALB} / \mathrm{c}$ mice to $\mathrm{N}$-nitroso-N-methylurethane, resulting in a rapidly growing and readily metastatic grade 4 carcinoma. CT26 colon carcinoma is one of the most commonly used cell lines for drug development [61]. Raoof et al. developed an electrochemical aptasensor to identify CT26 cells based on SBA-15-3-aminopropyltriethoxysilane and gold nanoparticle-modified graphite screen-printed electrodes with a thiol-terminated aptamer. Results obtained from cyclic voltammetry and electrochemical impedance spectroscopy studies showed that the fabricated aptasensor can recognize CT26 cells in the concentration ranges of $10-1.0 \times 10^{5}$ cells/ $\mathrm{mL}$ and $1.0 \times 10^{5}-6.0 \times 10^{6}$ cells $/ \mathrm{mL}$, respectively, with a detection limit of 2 cells $/ \mathrm{mL}$ [62]. To increase the selectivity and sensitivity, Zhang et al. developed nanohybrids of Cr-based metal-organic frameworks and cobalt phthalocyanine nanoparticles for determining CT26 cells. The proposed electrochemical cytosensor showed good detection performance for CT26 cells. Very low LOD values of 36 and 8 cells/mL were obtained using electrochemical impedance spectroscopy and differential pulse voltammetry, respectively, within a wide linear concentration range of CT26 cell suspensions from 50 cells $/ \mathrm{mL}$ to $1 \times 10^{7}$ cells $/ \mathrm{mL}$ [63]. Exosomes have attracted great interest as novel biomarkers in cancer diagnosis. Recent studies have shown that CRCderived exosomes have great potential for CRC diagnosis [64]. Yang et al. developed an electrochemical biosensor for detecting CRC-derived exosomes by covalent organic framework nanocomposites functionalized with para-sulfocalixarene hydrate-modified gold nanoparticles and horseradish peroxidase. The proposed method shows a linear range from $5 \times 10^{2}$ to $5 \times 10^{7}$ particles $/ \mu \mathrm{L}$, with a detection limit of 160 particles/ $\mu \mathrm{L}[65]$.
Hepatocellular carcinoma (HCC) is the most common form of liver cancer and has become a major health problem worldwide, with the number of cancer-related deaths steadily increasing [66]. $\alpha$-fetoprotein (AFP), a 70-kDa glycoprotein, is a biomarker of HCC. It is found in the yolk sac and is secreted by the fetal liver [67]. Lin et al. developed an electrochemical immunosensor based on a carbon paste electrode constructed from room-temperature ionic liquid $\mathrm{N}$-butylpyridinium hexafluorophosphate and gold nanoparticles to detect AFP in human serum. AFP concentration could be measured in a linear range of $0.50-80.00 \mathrm{ng} / \mathrm{mL}$ with a detection limit of $0.25 \mathrm{ng} / \mathrm{mL}$ [68]. To increase the sensitivity, Yang et al. proposed an electrochemical immunosensor for detecting AFP using a hedgehog-like $\mathrm{Bi}_{2} \mathrm{~S} 3$ based biosensor in a wide range of $0.01-20 \mathrm{ng} / \mathrm{mL}$ with a low detection limit of $0.005 \mathrm{ng} / \mathrm{mL}$ [69].

Prostate cancer $(\mathrm{PCa})$ is the second most common cancer and was the fifth leading cause of cancer-related deaths in men in 2020 [50]. Prostate-specific antigen (PSA)/human kallikrein-3 remains standard as the primary and most preferred diagnostic and detection method. In 1994, the US Food and Drug Administration (USFDA) approved PSA and digital rectal examination for the diagnosis and detection of PCa [70]. To enhance the accuracy of PCa diagnosis, several studies have reported the diagnosis of PSA with another cancer biomarker, vascular endothelial growth factor (VEGF). Due to the different types of procedures, VEGF and PSA detection is error-prone, relatively time-consuming, and expensive. Yang et al. demonstrated a graphene oxide/ ssDNA (GO-ssDNA)-based biosensor integrated with dual antibody-modified PLLA NPs to amplify electrochemical signals for the effective capture and rapid electrochemical capture of VEGF and PSA in serum samples from PCa patients. The detection limits for VEGF and PSA were $50 \mathrm{pg} / \mathrm{mL}$ and $1 \mathrm{ng} / \mathrm{mL}$, respectively, and achieved a wide linear range of $0.05-100 \mathrm{ng} / \mathrm{mL}$ for VEGF and $1-100 \mathrm{ng} /$ $\mathrm{mL}$ for PSA. In addition, progress has been made to reduce the time of detection within 60 min [71].

Gastric cancer is responsible for over one million new cases in 2020 and an estimated 769,000 deaths [50]. Studies have shown that cancer antigen 72-4 (CA72-4) has prognostic value in gastric cancer [72]. To detect CA72-4, Wei et al. developed an electrochemical immunosensor constructed by modifying a glassy carbon electrode with reduced graphene oxide-tetraethylene pentaamine for effective immobilization of primary anti-CA72-4 antibody with the secondary antibody adsorbed onto PtPd. The resulting PtPd-Fe3O4-Ab2 was used as a label for the preparation of an immunosensor to detect CA72-4. The electrochemical immunosensor exhibited a wide linear range of $0.001-10 \mathrm{U} / \mathrm{mL}$ with a low detection limit $(0.0003 \mathrm{U} / \mathrm{mL})$ [73]. Wei et al. improved the sensitivity and detection limit by using nanoporous gold film as the sensor platform and polyaniline-Au asymmetric 
multicomponent nanoparticles as labels. The developed immunosensor exhibited a wide linear range $(2-200 \mathrm{U} / \mathrm{mL})$ with a detection limit of $0.10 \mathrm{U} / \mathrm{mL}$ [74].

Acute lymphoblastic leukemia (ALL) is a common, fatal cancer that typically starts in the bone marrow and produces large numbers of immature white blood cells. The early detection of ALL is essential for the treatment of patients with suspected leukemia [75]. Rahimi-Nasrabadi et al. proposed an electrochemical aptasensor for detecting leukemia cancer cells (CCRF-CEM) through the superior catalytic effect of copper sulfide-graphene nanocomposite as a label and Au-GR nanocomposite as a sensing platform. This sensor has a linear range of $50-1 \times 10^{6}$ cells $/ \mathrm{mL}$, with a LOD of 18 cells $/ \mathrm{mL}$ in human blood serum samples [76].

\subsection{Coronaviruses}

Coronaviruses are a diverse group of viruses that infect a variety of animals and can cause mild or severe respiratory infections in humans. In December 2019, a novel coronavirus, severe acute respiratory syndrome coronavirus 2 (SARS-CoV-2), emerged in the city of Wuhan, China, resulting in unusual viral pneumonia. Because it is highly contagious, this novel coronavirus disease, also known as coronavirus disease 2019 (COVID-19), has rapidly spread worldwide. The ongoing outbreak of COVID-19 poses a tremendous threat to public health worldwide. Symptoms of infection include fever, fatigue, dry cough, sputum production, headache, hemoptysis, diarrhea, loss of appetite, sore throat, chest pain, chills, nausea, and vomiting [77]. Early and immediate diagnosis can play an important role in making appropriate decisions for the isolation of infected patients, thus slowing the spread of this infectious disease [78]. In general, reverse transcription-polymerase chain reaction (RT-PCR)-based tests for the detection of viral RNA are considered the gold standard method for diagnosing COVID-19. However, RT-PCR methods are usually tested in centralized laboratories/hospitals by trained personnel and may not be readily available or inexpensive in many countries. To overcome these issues, an electrochemical approach has become an especially well-suited technique for the detection of SARS-CoV-2 antibodies. Chaiyo et al. demonstrated a paper-based electrochemical platform as a screening tool for detecting SARS-CoV-2 immunoglobulin. The sensing system relies on the disruption of the redox conversion $\left(\left[\mathrm{Fe}(\mathrm{CN})_{6}\right]^{3-/ 4-}\right)$ triggered by immunocomplex formation between the captured immunoglobulins produced in response to SARS-CoV-2 in humans with the immobilized spike protein of SARS-CoV-2. The rapid and sensitive detection of SARS-CoV-2 antibody was recorded in $30 \mathrm{~min}$ with a detection limit of $1 \mathrm{ng} / \mathrm{mL}$, three times more sensitive than the colorimetric lateral flow immunoassay (LFA). In addition, this paper-based electrochemical device can detect target antibodies in the clinical serum of patients and has an acceptable sensitivity of $100 \%$ and a specificity of $90 \%$ [79].

In addition, viral nucleic acid testing should be used for accurate diagnosis of active COVID-19 infection. Chaibun et al. proposed an electrochemical biosensor based on multiplex rolling circle amplification (RCA) for the rapid detection of the nucleocapsid $(\mathrm{N})$ and spike (S) genes of SARS-CoV-2 from clinical samples. The assay involves sandwich hybridization of RCA amplicons with probes functionalized with redox-active labels, which were subsequently detected by differential pulse voltammetry (DPV). This assay can detect up to 1 copy $/ \mu \mathrm{L}$ of viral $\mathrm{N}$ or $\mathrm{S}$ gene within $2 \mathrm{~h}$ without the need for a thermocycler. Clinical samples were also used to evaluate the performance of assays, which were found to be consistent with the quantitative RT-PCR results. The performance of the assay using clinical samples was comparable to that of RT-qPCR, the current standard for detection of SARS-CoV-2 but showed no false-positive results [80]. Cady et al. developed a multiplexed gratingcoupled fluorescent plasmonic (GC-FP) biosensor platform to rapidly and accurately measure antibodies against COVID-19 in human blood serum and dried blood spot samples. The GC-FP platform measures antibody-antigen binding interactions for multiple targets in a single sample and has a selectivity and sensitivity of $100 \%$ when measuring serum IgG levels against three COVID-19 antigens: spike S1, spike S1S2, and the nucleocapsid protein. GC-FP can detect antibodies at dilutions as low as 1:1,600 titer, and thus has the necessary sensitivity for determining clinically and therapeutically relevant seroconversion status [81].

\section{Recent advances in electrochemical sensors for the detection of disease}

The sensitivity and function of electrochemical sensors are important factors for use in early disease diagnosis, which requires the detection of small amounts of biocomponents. Among the characteristics of an electrochemical sensor, the ability to recognize an analyte is the most important factor in determining its sensitivity. Therefore, efforts to improve the sensitivity of the sensor have been actively made, which has been performed in various ways with the development of materials and biotechnology [82]. The factors that determine the sensitivity of the sensor include a receptor site that recognizes a target material and a transducer site that generates a signal after recognition and converts it into the desired signal form [83]. Antibodies, peptides, and genes capable of recognizing a target material are attached to the receptor site, and their recognition ability is determined according to affinity with the target material. The need for a new approach has begun to be emphasized, as there is a limit to improving the sensitivity of the sensor with the existing immobilization 
method alone [84]. The introduction of enzymes and aptamers for target material (biomarker) detection, immobilization, and stabilization technology also plays an important role in improving the performance of the sensor.

At the transducer site and enabled the recognition of even small amounts of materials as a sensor signal [85]. When converting a change that occurs during a biological reaction on the sensor surface into an electrical signal, efforts are being made to amplify the signal using a conductive material [86]. The presence of a target material is often verified by measuring the change in the resistance value of the electrode surface and the movement of the charge on the sensor surface that occurs during the antigen-antibody reaction. To date, studies to improve sensitivity and differentiate nonspecific signals have mainly been conducted [87]. Appropriate surface modification and novel nanotechnology-based approaches offer the potential to further amplify the signal to increase sensitivity. Among them, the development of nanomaterials has led to innovative advances in diagnostic technology by utilizing the physical and chemical properties of the material itself, as well as signal amplification and improved biosensor sensitivity [88].

\subsection{DNA and RNA sensors}

The DNA-electrochemical biosensor is generated using an electrode with a DNA probe immobilized on its surface and is used to detect DNA-binding molecules that interact and induce changes in the DNA structure and electrochemical properties, which are further translated into an electrical signal [89]. For accuracy, DNA must be immobilized on the electrode surface. Many recent studies have shown the use of nanomaterials such as graphene, carbon nanotubes, or nanoparticles as electrodes [90]. MicroRNAs (miRNAs) are one of the most well-studied non-coding RNAs with important roles in gene regulation, some of which are poorly regulated in certain cancer types. Some miRNAs regulate genes essential for cellular homeostasis, and these changes lead to abnormal biological changes, including unregulated cell proliferation, angiogenesis, metabolism, and apoptosis, leading to malignant tumor formation. Malignant transformation alters cellular and cellular state-specific miRNA expression profiles in healthy tissues. Moreover, miRNAs can induce malignant tumor formation by repressing tumor suppressor genes or increasing oncogene expression, thus highlighting the importance of miRNAs in malignant transformation and as a biomarker to further classify cancer types [91]. Figure 6 shows sensitive miRNA electrochemical detection platform. Arduini et al. designed a cost-effective electrochemical paper-based sensor to detect miRNA-492, a biomarker for pancreatic ductal adenocarcinoma. They used highly specific peptide nucleic acids as the recognition element to avoid issues related to stability and $\mathrm{pH}$ effects, which often represent the bottleneck when DNA/RNA are adopted as probes. The electrochemical strips were able to detect miRNA-492 down to $10 \mathrm{nM}$ in a few microliters of sample, within an hour, showing good selectivity with only one mismatch along the sequence in the presence of interfering species [92]. Shiddiky et al. developed an electrochemical sensor using a mesoporous gold electrode fabricated by block polymeric micelles to target a carcinoma biomarker, miR-9-2. This method avoids cumbersome PCR and enzymatic amplification steps. This is a single-step assay capable of detecting a wide dynamic linear range of $100 \mathrm{aM}$ to $1 \mathrm{nM}$ with an ultra-low limit detection (100 aM) of miRNAs [93]. Jou et al. designed an isothermal, dual signal amplification strategy to translate a biosensing event for the pancreatic cancer biomarker miR-196b into electrochemical signals. The platform is based on a polydopamine-AuNP composite that provides a functionalizable interface for the sensitization of electrode probes and a suitable hydrophilic interface for an aqueous biosensing reaction, as confirmed by water contact angle measurements and cyclic voltammetry. The novel electrochemical biosensor provided a detection limit of $0.26 \mathrm{pM}$, excellent assay reproducibility with a coefficient of variance value of $8.5 \pm 3.1 \%$, and a recovery rate of $105 \pm 4.1 \%$ obtained from spiked real human serum samples [94]. Zhou et al. fabricated an electrochemical biosensor to detect ultra-trace miRNA-141, a biomarker for prostate cancer. The system was based on click chemistry-mediated enzyme-assisted target recycling and amino and thiol group multi-labeled functionalized fullerene nanoparticle dualamplified strategy. This dual amplification detection system showed remarkable analytical performance for the detection of miRNA-141 at concentrations ranging from $0.1 \mathrm{pM}$ to $100 \mathrm{nM}$, yielding a detection limit of $7.78 \mathrm{fM}$ [95]. In addition, it has been found that the expression of miR-146a is upregulated in neurons from patients with AD [96]. Balal et al. developed a microRNA-based electrochemical biosensor for the quantification of miR-146a, a biomarker of dementia-related disease pathways. The linear dynamic ranges, limits of quantitation, and relative standard deviations of the proposed bioassay were $10 \mathrm{pM}$ to $1 \mu \mathrm{M}, 10 \mathrm{pM}$, and $1.59 \%$, respectively. The developed method provides a more accurate and sensitive tool used in clinical applications for the early detection of neurodegenerative diseases [97].

Electrochemical biosensors based on DNA probes are widely used for miRNA detection because of their advantages, including a high sensitivity, rapid reaction times, and simple operation. A challenge in the design of these biosensors is controlling the density and orientation of the recognition probes. This may inhibit the binding activity of single-stranded DNA to the target, reduce sensitivity, and affect the stability of the biosensor. To solve this problem, a three-dimensional DNA tetrahedral structure probe (TSP) was introduced into the system. As a new type of DNA 
(a)

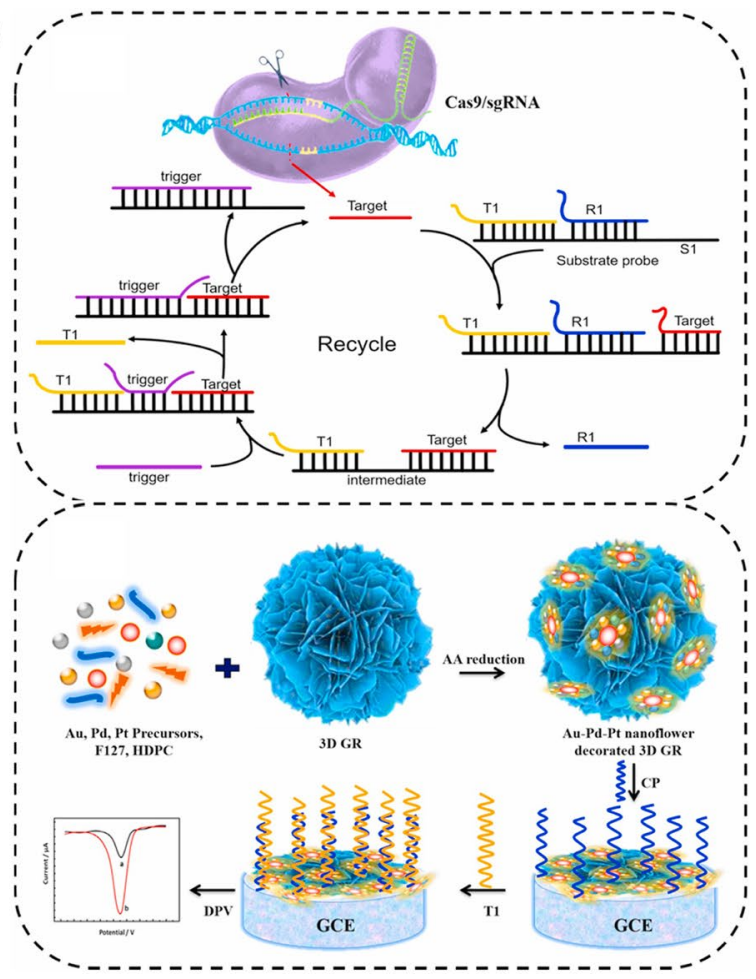

Fig. 6 a Schematic of the principle of the CRISPR/Cas9-triggered ESDR based on a 3D GR/AuPtPd nanoflower biosensor. Reproduced with permission from Ref. [12]. Copyright (2021) Elsevier. b Schematic representation of a preparation of mesoporous $\mathrm{Au}$ electrode (MPGE) via electrodeposition of gold (III)-containing polymeric (block) micelles. Reprinted with permission from Ref. [93]. Copyright (2020) Elsevier. c Gel electrophoresis analyses of the

structure, TSPs can be attached to Au electrode surfaces as capture probes based on their thiolated DNA tetrahedral nanostructures. These probes provide excellent mechanical stiffness and structural stability. A typical DNAzyme formed by interacting hemin with a single-stranded guaninerich nucleic acid sequence, G-quadruplex-hemin, serves as a horse-radish-peroxidase (HRP)-like enzyme for electrocatalysis. At the same time, duplex-specific nucleases (DSNs) can hydrolyze DNA in DNA-RNA hybrids but have little effect on single-stranded DNA. The ability to discriminate between perfect and imperfectly matched short duplexes contributes to DSN-mediated signal amplification strategies. Zhang et al. developed a novel electrochemical biosensor based on TSP and DSN for the rapid detection of miRNAs, and improved detection efficiency by using TSP to control the density and orientation of probes on the electrode surface. In contrast, the synergistic effect of G-quadruplex-hemin and l-cysteine generated a stable electrochemical signal, and signal enhancement was achieved by DSN-assisted target recycling. Through parameter optimization and evaluation, the proposed biosensor showed good selectivity, satisfactory sensitivity, and acceptable accuracy. They also evaluated the (b)

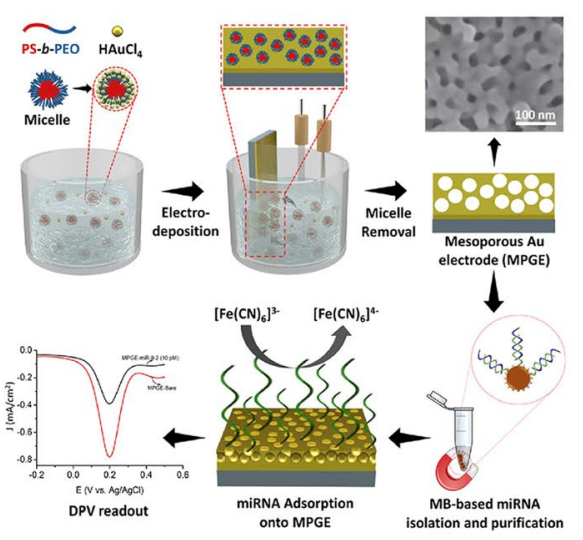

(c)

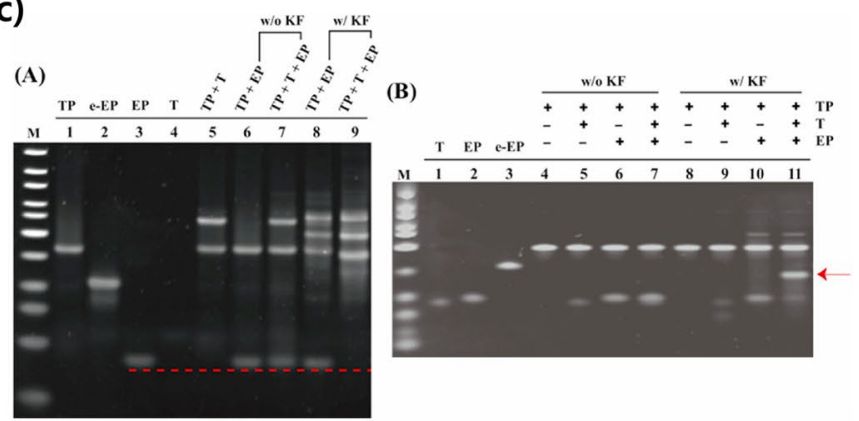

translational biosensing event between a target miR-196b and a target probe via Klenow fragment-assisted dual amplification for the detection of target miR-196b using a native gel and $7 \mathrm{M}$ urea denaturing gel. M indicates the DNA markers for 10-300 bp. Each lane: $100 \mathrm{nM}$. Reproduced with permission from Ref. [94]. Copyright (2021) Elsevier

expression level of miRNA-21 in clinical serum samples from patients with cancer with acceptable results [98].

Nanozymes are a class of nanomaterials with catalytic properties that mimic enzymes, including PtNPs and metal-organic frameworks (MOFs). MOF nanozymes coordinated with other functional species with multi-layered features show obvious advantages for catalytic activities, which have been explored for applications in sensing, catalysis, and tumor treatment. Ding et al. developed a novel electrochemical biosensor for exosomal miRNA-21 detection using a target-triggered cascade primer exchange reaction with the MOF@Pt@MOF nanozyme. The three-layer nanozyme not only decomposes $\mathrm{H}_{2} \mathrm{O}_{2}$ to generate amplified electrochemical signals, but also offers a new concept for synthesizing other high-performance catalysts [99]. Li et al. proposed a soft template-directed wet chemical approach for the controllable preparation of $2 \mathrm{D} \mathrm{MnO}_{2}$ nanoflakes with dual enzyme-like activities. Through the dual enzyme-like activity, $2 \mathrm{D} \mathrm{MnO} 2$ nanoflakes showed high activity in catalyzing the oxidation of $\mathrm{O} 2$ to $\mathrm{ROS}$ and greatly reduced the DPV peak current through MB removal. In addition, the 2D MnO2 nanoflakes exhibited unique responses to ssDNA. 
Because of ssDNA sensitivity and dual enzyme-like activity, a homogeneous electrochemical biosensor for 2D MnO2 nanoflake-based miRNAs was developed with an excellent linear range of $0.4-100 \mathrm{nM}$ for detecting miRNA let-7a, a biomarker for cancer [100].

Circulating tumor DNA (ctDNA) derived from tumors is present in the plasma of cancer patients [101]. Lan et al. synthesized highly active carbon (HAC)-AuPt nanocomposites and used them as labels for signal amplification to build a novel sandwich-type biosensor for the electrochemical analysis of ctDNA of breast cancer. The combination of HAC and AuPt alloy further enhanced the current response and provided sufficient sites to anchor the signal probe while preventing the agglomeration of nanoparticles. As a result, the proposed HAC-AuPt-based biosensor exhibited excellent performance for ctDNA detection [102]. Xu et al. constructed a CRISPR/Cas9 triggered entropy-driven strand displacement reaction (ESDR) system based on a 3D GR/ AuPtPd nanoflower biosensor to detect mutated epidermal growth factor receptor (EGFR) ctDNA for the first time. By combining the advantages of site-specific cleavage of Cas9/ sgRNA with the fast amplification kinetics of ESDR, Cas9ESDR has shown remarkable performance, a high specificity, and signal enhancement [132].

\subsection{Enzyme-based sensors}

Enzyme-based sensors are highly specific catalytic biosensors whose recognition elements are extremely selective enzyme molecules immobilized on a transducing surface, known as an electrode. Enzymes catalyze electrochemical reactions involving electroactive products or transducers and measure electrical changes in the sample [103]. In Fig. 7, schematic representation of enzyme-based electrochemical sensors and electrochemical characteristics are demonstrated. Kim et al. immobilized pyranose oxidase (POx) on carbon nanotubes (CNTs) to investigate the electrochemical performance of POx-based biosensors and biofuel cells for glucose detection. POx was immobilized on CNTs via the enzyme precipitate coating (EPC) method, which showed both improved enzyme loading and enzyme stability when compared to covalent attachment and enzyme coating methods. With increased enzyme loading, the EPC-POx-based electrodes can generate a greater number of electrons per unit geometrical surface area of the enzyme electrode. The combination of high POx loading and improved electron transfer rate of POx led to both a high glucose sensitivity in the biosensor and a high maximum power density in the biofuel cells when EPC-POx-based enzyme electrodes are utilized. The stability of the EPC-POx-based electrode was high, with $65 \%$ of the initial activity after 34 days at room temperature, while covalent attachment and enzyme coating methods showed $9.2 \%$ and $26 \%$ of their initial activities, respectively [13]. Wei et al. encapsulated laccase into ZIF-8 during the in situ growth of ZIF-8 on cellulose acetate nanofibers. The electrode was synthesized by modification with MWCNTs and AuNPs. The proposed biosensor demonstrated excellent stability in continuous work for up to $15 \mathrm{~h}$ [104]. Bi et al. designed a bi-enzyme encapsulated DNA flower (DF) structure with rolling circle amplification to achieve a versatile fabrication of enhanced cascade biocatalysis and electrochemical biosensors. One-pot encapsulation of glucose oxidase (GOx) and horseradish peroxidase (HRP) into DF enables programmable and spatial control of micron-scale double-enzyme molecules. Using the GOx/ HRP DFs as an excellent sensing interface, a glucose electrochemical biosensor is readily constructed, achieving a LOD as low as $3.35 \mu \mathrm{M}$ [105].

To detect L-fucose, a biomarker of digestive organ cancer and cirrhosis, Nakamura developed an amperometric biosensor utilizing direct electron transfer-type bioelectrocatalysis of pyrroloquinoline quinone (PQQ)-dependent pyranose dehydrogenase from Coprinopsis cinerea (CcPDH). With an applied potential of $-0.1 \mathrm{~V}$, the oxidation of AA, DA, and UA was avoided, and 1-fucose oxidation still provided a clear catalytic current. The PQQ domain-modified AuNP electrode exhibited high sensitivity with a useful linear range of 0.1-1 mM and a low detection limit of $13.6 \mu \mathrm{M}$ [106]. Ju et al. developed a biosensor with an organic electrochemical transistor for the analysis of cell surface glycan expression to detect mannose and galactose in HeLa cells using Con A and PNA as signal lectins. This strategy can be conveniently accomplished by covalently capturing target cells at the gate electrode surface, and then using the corresponding lectins to specifically recognize cell-surface glycans. Both the channel current and effective gate voltage changes show good relativity with the cell number used in the capture process. To detect mannose and galactose on the cell surface by simulating cells using mannosamine- or $\mathrm{N}$-acetyl-D-galactosaminemodified magnetic microspheres and recognizing specific glycans using HRP-labeled Con A or PNA. Two quantitative methods were proposed [107]. Sode et al. developed a multiplexed direct electron transfer (DET)-type lactate and glucose enzyme sensor with a fusion enzyme between an engineered 1-lactate oxidase derived from Aerococcus viridans, AvLOx A96L/N212K mutant, which minimized its oxidase activity and constructed a b-type cytochrome protein. A mutation was introduced into the fusion enzyme to increase the $\mathrm{Km}$ value and eliminate its substrate inhibition to construct "b2LOxS." The detection range of the sensor with b2LOxS was expanded to $10 \mathrm{mM}$. The sensors achieved simultaneous detection of lactate and glucose without crosstalking error, with the detected linear ranges of $0.5-20 \mathrm{mM}$ for lactate and $0.1-5 \mathrm{mM}$ for glucose, sensitivities of $4.1 \mathrm{nA} /$ $\mathrm{mM} \bullet \mathrm{mm}^{2}$ for lactate and $56 \mathrm{nA} / \mathrm{mM} \bullet \mathrm{mm}^{2}$ for glucose, and LODs of $0.41 \mathrm{mM}$ for lactate and $0.057 \mathrm{mM}$ for glucose. 
(a)

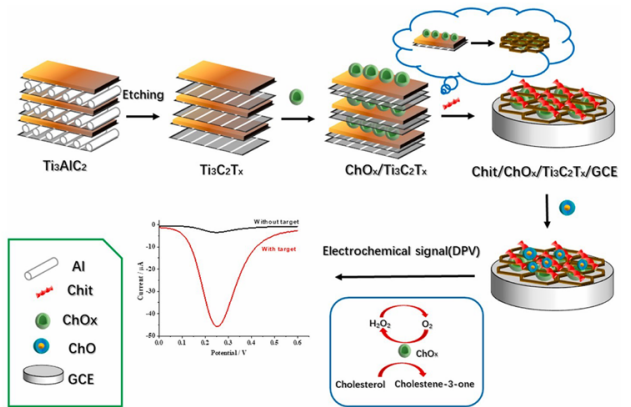

(b)

A Signal-on mode

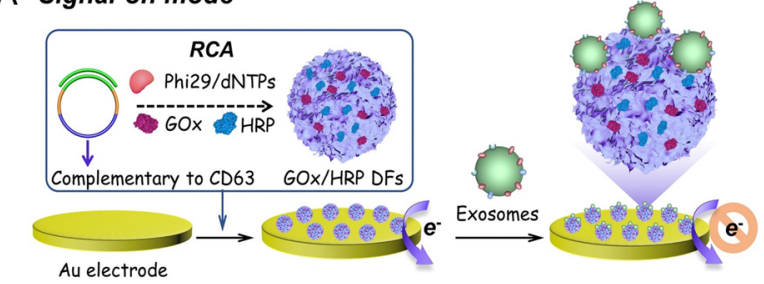

$\mathrm{B}$

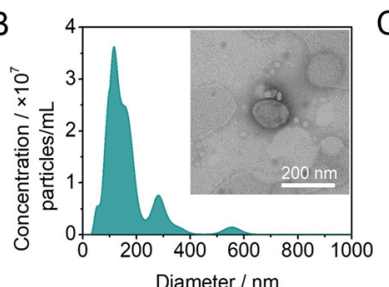

D
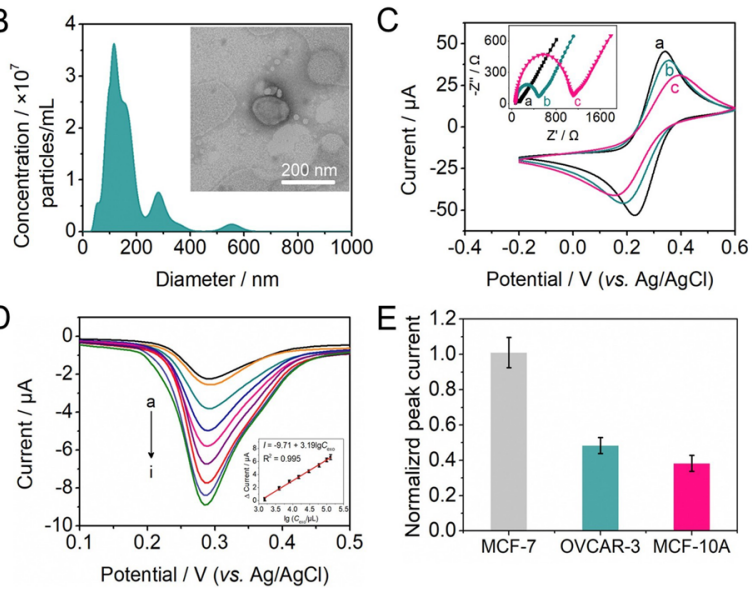
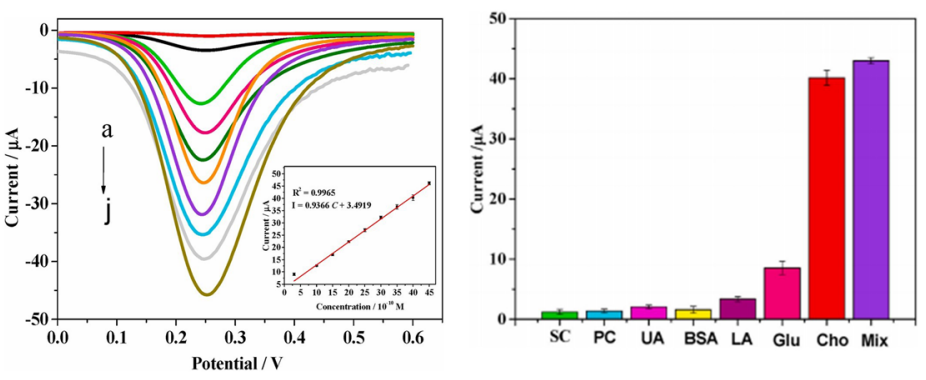

(c) A Signal-off mode
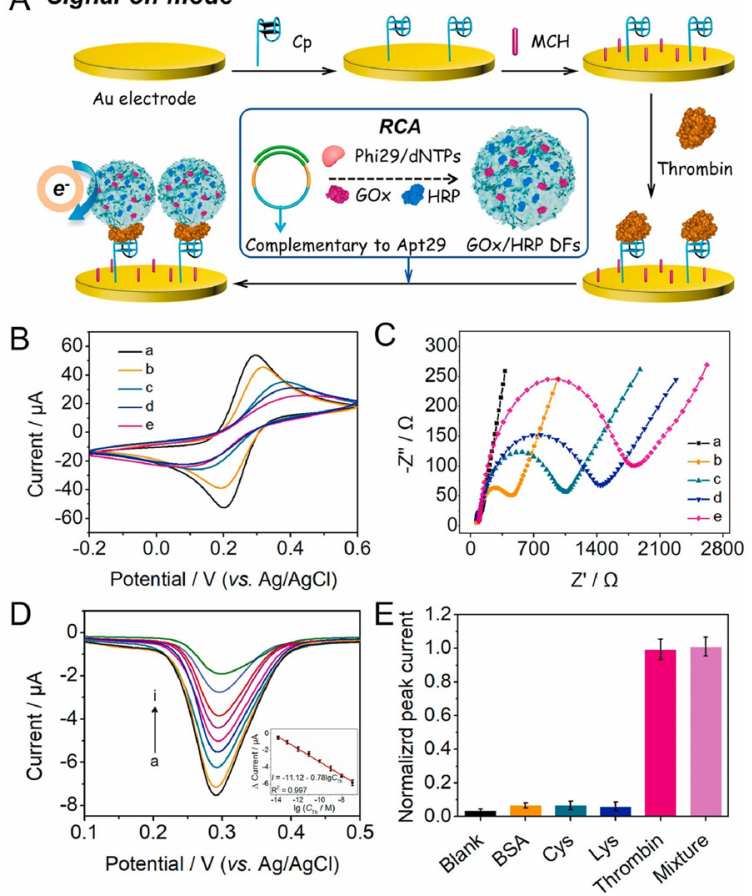

Fig. 7 a A schematic representation of the fabrication of the Chit/ $\mathrm{ChOx} / \mathrm{Ti} 3 \mathrm{C} 2 \mathrm{Tx} / \mathrm{GCE}$, and a possible reaction mechanism of cholesterol at the modified GCE. Reproduced with permission from Ref. [109]. Copyright (2021) Elsevier. b "Signal-on" electrochemical exosomes aptasensor using CD63-incorporated GOx/HRP DFs

The lactate sensor can operate continuously for $6.5 \mathrm{~h}$ using the newly developed DET-type lactate oxidase [108]. Hou et al. synthesized a MXene $\left(\mathrm{Ti}_{3} \mathrm{C}_{2} \mathrm{~T}_{\mathrm{x}}\right)$-based enzymatic electrochemical biosensor to detect cholesterol constructed by utilizing the beneficial properties of MXene and chitosan. The DPV response for the determination of cholesterol is generated via the cholesterol oxidase reaction, which is the selective oxidation of cholesterol to cholest-4-en-3-one and $\mathrm{H}_{2} \mathrm{O}_{2}$. The fabricated biosensor showed a low detection limit $(0.11 \mathrm{nM})$ and high sensitivity of $132.66\left(-1 \mathrm{~cm}^{-2}\right)$. In addition, the long-term stability of the biosensor was assessed by monitoring $2 \mathrm{nM}$ cholesterol applied intermittently for DPV measurements after storage at room temperature for 15 days [109]. as sensing interface and specific recognition element. c "Signal-off" electrochemical dual-aptamer biosensor for thrombin detection using Apt15 as capture probe and Apt29-incorporated GOx/HRP DFs as amplified labels. $\mathbf{b}$ and $\mathbf{c}$ Reproduced with permission from Ref. [105]. Copyright (2021) Elsevier

\subsection{Nanoparticles}

Nanomaterials (NM), materials with structural element sizes of 1-100 nm, differ significantly from similar macroscopic materials. In biosensors, NMs are used to improve the basic analytical properties of biosensors, such as sensitivity, LOD, linear detection range, selectivity, reproducibility, stability, and response time. In particular, the unique properties of NMs are their high surface-to-volume ratio, a significant increase in the sensitive surface of the transducer, and effective enzymatic immobilization. NMs are also characterized by a high electrical conductivity, better magnetic properties, and enhanced catalytic activity, among others, which are important for biosensors. Furthermore, the surface of NMs 
can be easily modified with different chemical groups, which is essential for interaction with biomaterials in biosensors and other biotechnology assays. Doped NMs also provide a flexible method for obtaining highly effective sensors [110].

The ability of AuNPs to enable the stable immobilization of biomolecules that retain their bioactivity is a major advantage for biosensor fabrication. Furthermore, gold nanoparticles enable direct electron transfer between redox proteins and bulk electrode materials, allowing electrochemical sensing without the need for electron transport mediators. The properties of gold nanoparticles, such as high surface-to-volume ratio, high surface energy, ability to reduce protein-metal particle distance, and function as an electron-conducting path between the prosthetic group and the electrode surface, have been argued for the facilitation of electron transfer between redox proteins and electrode surfaces. Gold nanoparticles have also been demonstrated to constitute useful interfaces for the electrocatalysis of redox processes of molecules, such as $\mathrm{H}_{2} \mathrm{O}_{2}, \mathrm{O}_{2}$, or NADH, which are involved in many important biochemical reactions [111]. Figure 8 introduces the construction and detection of the electrochemical biosensor using gold nanoparticles. Park et al. constructed an electrochemical biosensor using

(a)
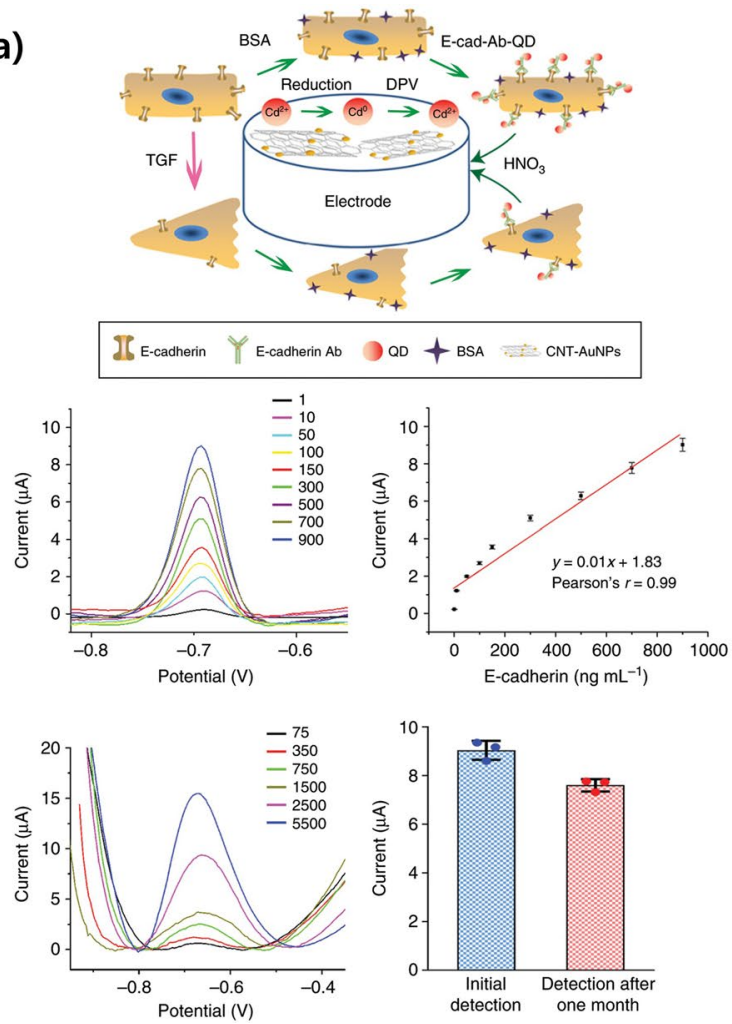

Fig. 8 a Construction of the electrochemical biosensor of EMT. Detection of E-cadherin at different protein levels and with different number of cells. Reproduced with permission from Ref. [113]. Copyright (2020) Springer. b Immunosensor preparation mechanism dia-

(b)
anti-HEV antibody conjugated to nitrogen- and sulfur-codoped graphene quantum dots and gold-embedded PANI nanowires as the electrode matrix to detect hepatitis E virus, the leading cause of acute viral hepatitis. The nanocomposites show excellent electroactivity in analyte solutions, which can be applied for virus detection by impedimetric processes [14]. Cao et al. developed a ratiometric electrochemical immunosensor to detect procalcitonin, which is a biomarker of septicemia and pyemia. The biosensor was constructed by modifying gold nanoparticles on the surface of $\mathrm{SiO}_{2}$ to increase the overall conductivity of $\mathrm{SiO}_{2}$, enhance the electrochemical reaction signal, and improve the sensitivity of the immune sensor [112]. Liu et al. established an electrochemical biosensor that detects epithelialmesenchymal transition, which plays a critical role in tumor progression. The biosensor was developed using the unique performance of a quantum dot nanocomposite modified with multi-walled carbon nanotube-gold nanoparticles to enhance the sensitivity of the biosensor [113]. Qian et al. developed a surface-enhanced Raman scattering (SERS) sensor for detecting $\mathrm{H}_{2} \mathrm{O}_{2}$ by modifying newly synthesized 2-mercaptohydroquinone molecules on the surface of gold nanoparticles. A good distribution of AuNPs creates many
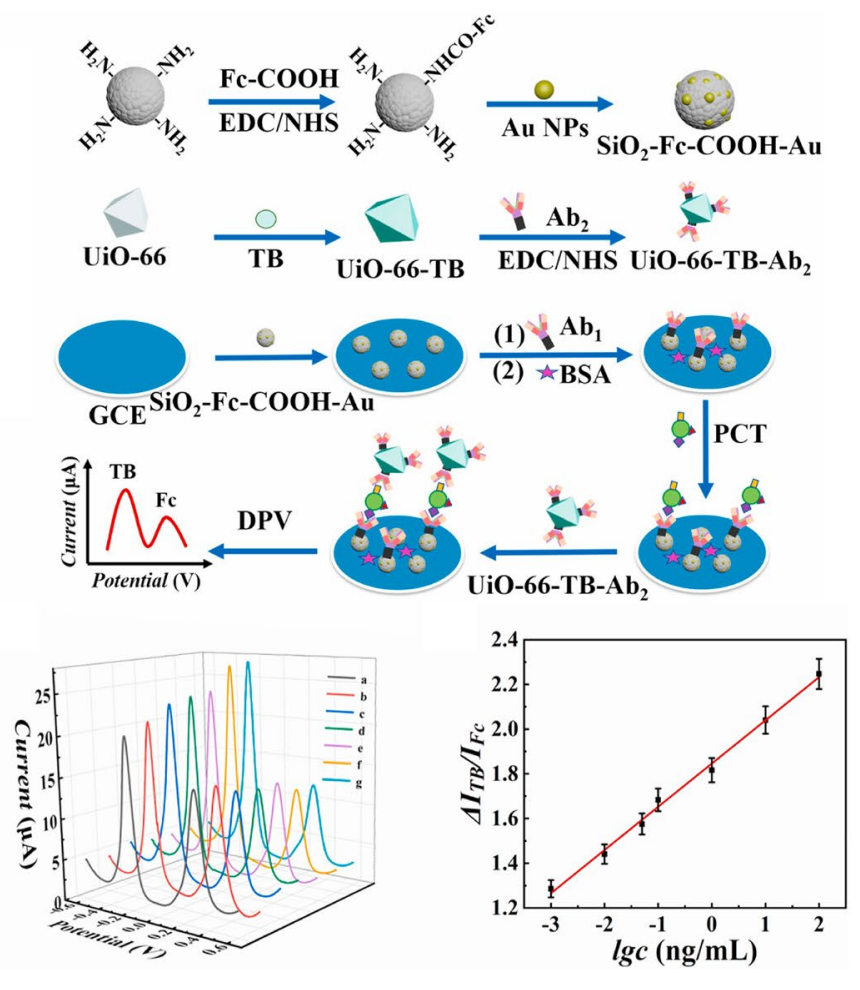

gram. The immunosensor response to DPV signals for detecting different concentrations of PCT. Reproduced with permission from Ref. [112]. Copyright (2021) Elsevier 
"hotspots" on the fabricated substrate, leading to a high SERS performance [114].

Silver nanoparticles (AgNPs) offer obvious advantages for electrochemical biosensor design, such as simple preparation procedures, size-dependent optical properties, facile surface modification, high surface area, and low oxidation potential [115]. Hogiu et al. developed an inexpensive, portable platform for urea detection via electrochemistry by depositing AgNPs on commercial glucose test strips. The uniform deposition of AgNPs improved the surface area and the electrochemical measurement performance. In addition, the presence of AgNPs on the surface of the working electrode and its interaction with the electrolyte act as a catalyst for the hydrolysis of urea, enabling its detection [116]. Xia et al. proposed an electrochemical biosensor for detecting p53 protein, a tumor suppressor, based on the interaction of cysteine thiols and AgNPs. AgNP networks formed in situ on the sensor electrode surface were utilized as electroactive reporters for signal readout. The biosensor is simple, cost-effective, and obviates the modification of nano-labels for molecular recognition [117]. Permual et al. produced a green graphene nanofiber laser biosensor (LSG-NF) decorated with oil palm lignin-based synthetic AgNPs bonded with a single strand of DNA for the production of a tuberculosis bioelectrode to detect TB target DNA. AgNPs were synthesized from palm oil lignin, an eco-friendly and costeffective method [118].

Platinum nanoparticles (PtNPs) differ from nanoparticles of other metals in their ability to catalyze the decomposition of $\mathrm{H}_{2} \mathrm{O}_{2}$, a common product of oxidation reactions. The oxidation or reduction of hydrogen peroxide results in the adsorption of electrons, which can be measured using amperometric methods. Hydrogen peroxide decomposes naturally, but the catalyst significantly accelerates this reaction and increases the biosensor response. Conventional platinum electrodes have the same catalytic activity, but the use of platinum nanoparticles significantly increases the surface area and number of catalytic sites. Electrode transformation with platinum nanoparticles can be accomplished by chemical reduction and electrochemical and photochemical deposition of platinum compounds [110]. Lee et al. immobilized glutamate oxidase on top of printed platinum nanoparticles (PtNPs), multi-walled carbon nanotubes (MWCNTs), conductive polymer - poly (3,4-ethylenedioxythiophene) polystyrene sulfonate (PEDOT: PSS), and Ecoflex silicone rubber electrodes to fabricate microscale implantable glutamate sensors with a high sensitivity, linearity, and selectivity, as glutamate excitotoxicity is a biomarker of neurodegenerative diseases, such as PD and AD. The addition of PtNPs improved the electrocatalytic activity of the nanocomposite [119]. Recently, Huang et al. developed an electrochemical biosensor platform based on a nanostructured conductive gradient hollow fiber membrane fabricated with conductive
PANI and Pt NPs. Pt NPs increased the electrode area and catalytic current, thereby enhancing the sensitivity of biosensors [120].

Silicon nanostructures have been extensively developed for the rational fabrication of high-quality sensors and probes for bioimaging and biosensing applications. It is worth noting that silicon nanomaterials are biodegradable into easily extensible molecules and can be excreted from the body without evidence of in vivo toxicity [121]. Mesoporous silica nanoparticles (MSNs) can encapsulate vast amounts of materials in structural apertures and deliver these materials to targets with greater granularity [122]. Wu et al. proposed an electrochemical biosensor for detecting $\mathrm{DA}$, a biomarker for $\mathrm{AD}, \mathrm{PD}$, and schizophrenia. A core for the in situ chemical-oxidative polymerization of conductive polypyrrole was used by carbon-coated mesoporous $\mathrm{SiO}_{2}$ nanoparticles. The modified nanocomposites showed large peak currents for the DA oxidation reaction, revealing a very small charge-transfer resistance, suggesting that the electrochemical performance of the nanocomposites was enhanced [123].

\subsection{Carbon materials (CNT and graphene)}

Carbon-based nanomaterials are particularly useful and have been applied in various industries. Carbon nanotubes (CNTs) have excellent mechanical stability, large surface area, and good electrical conductivity owing to the orbital hybridization between adjacent carbon atoms, which can be used as electrode structures. There are two types of CNTs: single-walled and multi-walled. Single-walled carbon nanotubes (SWCNTs) exhibit excellent electronic and mechanical characteristics. Its large surface area can increase the quantity of immobilized enzymes, widen the reaction areas between the enzyme and the substrate, facilitate electrical conductivity, and increase the signal response of the biosensors [124]. Yu et al. demonstrated the fabrication of semiconducting single-walled carbon nanotube (sc-SWNT) fibers via wet-spinning for electrochemical biosensor platforms. The SWNTs were purified using thermal and acid treatments and separated into metallic SWNTs and sc-SWNTs. The scSWNTs were then wet-spun into the flexible fibers. Then, an enzyme capable of reacting with glucose was immobilized on the sc-SWNT fibers to investigate the utility of sc-SWNT fibers as an electrochemical biosensor platform. This gate effect was demonstrated for a fiber-type glucose sensor with a high sensitivity $(0.5 \mu \mathrm{M})$ [125]. Ghodssi et al. presented CNT-modified Au electrodes on a porous polyester tracketched transwell membrane for the dynamic, quantitative detection of serotonin (5-HT), a neurotransmitter involved in neuronal synaptic signaling in the brain and peripheral nervous systems, in cell media. The electrochemical characterization of SWCNT-coated Au electrodes showed increased 
electroactive surface area, 5-HT specificity, sensitivity, and saturation time, which are correlated with the CNT film drop-cast volume [126].

Multi-wall carbon nanotubes (MWCNTs) comprise multiple layers of concentric single-walled graphene cylinders [2]. MWCNTs are ideal materials for electrochemical biosensing because of their high electrical conductivity, large lengthto-diameter ratio, large surface area, and good mechanical strength [127]. Xu et al. developed a screen-printed carbon electrode-based electrochemical biosensor using Au nanocage (AuNC)/MWCNT-NH ${ }_{2}$ nanostructure to detect spiked long non-coding RNA metastasis-associated lung adenocarcinoma transcript 1 (MALAT1), a biomarker of non-small cell lung cancer. Au NCs combined with MWCNTs-NH2 resulted in higher degrees of electron transfer and high electrochemical activity, which significantly enhanced signal detection. The biosensor using Au NCs/MWCNTs-NH2 as a label exhibited a much greater electrochemical response

(a)
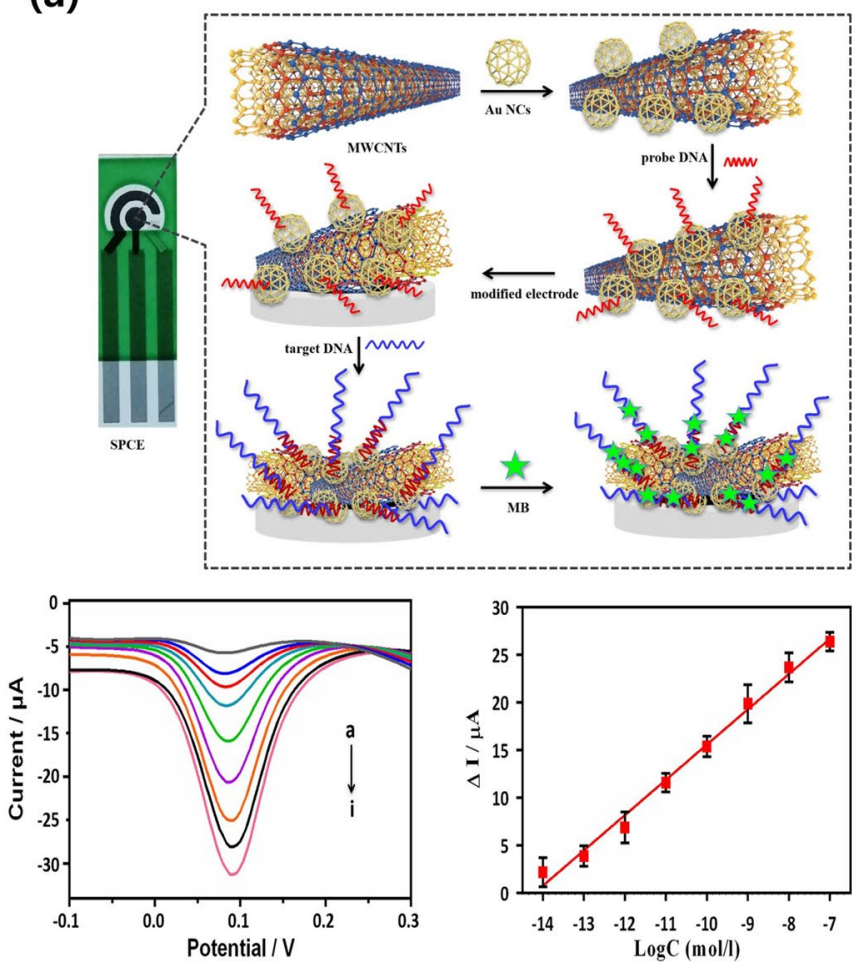

Fig. 9 a Schematic representation of the SPCE electrochemical DNA biosensor. DPV curves after hybridization, The calibration plot of peak current versus the logarithm of the concentration of target lncRNA MALAT1. Reproduced with permission from Ref. [15]. Copyright (2021) Springer. b Schematic representation of the fabrication and working of Tyr/ZnO-rGO/ITO biosensing platform. DPV response of Tyr/ZnO-rGO/ITO bioelectrodes towards different than that without MWCNTs- $\mathrm{NH}_{2}$ [15]. Figure 9a shows the screen-printed carbon electrode electrochemical DNA biosensor.

Graphene has a low throughput and is hydrophobic, which limits its usefulness in biosensor applications. However, graphene oxide (GO) and reduced graphene oxide (rGO) overcome this problem by increasing the hydrophilicity of the graphene layer, removing oxygen groups from the GO to achieve good electrical conductivity, and promoting surface modification for biomolecular immobilization [2]. Singh et al. demonstrated zinc oxide-reduced graphene oxide ( $\mathrm{ZnO}-\mathrm{rGO})$ nanocomposites as a transducer matrix for the sensitive detection of DA. ZnO-rGO thin films on indium-tin-oxide (ITO)-coated glass sheets followed by covalent attachment of tyrosinase (Tyr) enzyme on its surface. ZnO-rGO/ITO electrodes exhibit better electron transport than $\mathrm{ZnO}$ NP/ITO electrodes because of their high redox current and low peak separation potential.

(b)
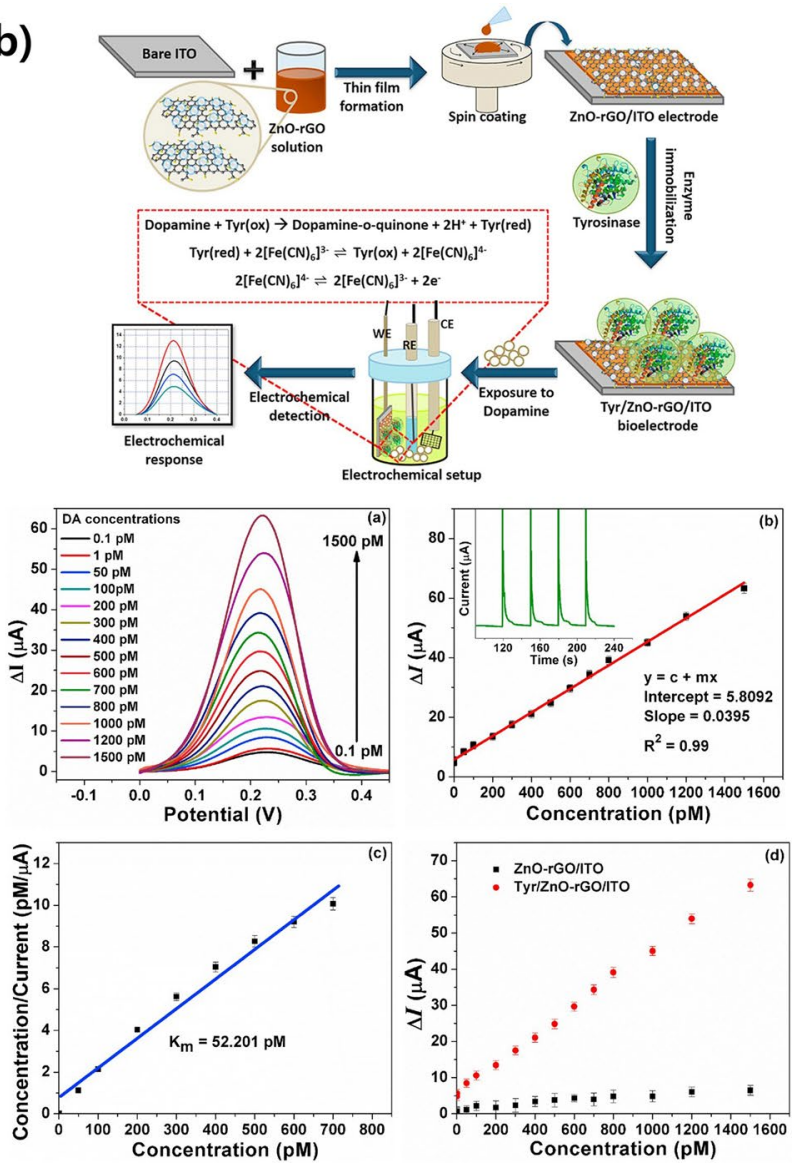

DA concentrations. Calibration curve plotted between DPV response current and exposed DA concentrations. Hanes plot to determine the Michaelis-Menten constant $(\mathrm{Km})$ associated with enzyme activity. Comparison of responses between $\mathrm{ZnO}-\mathrm{rGO} / \mathrm{ITO}$ and $\mathrm{Tyr} / \mathrm{ZnO}-\mathrm{rGO} /$ ITO electrodes towards different DA concentrations. Reproduced with permission from Ref. [128]. Copyright (2020) Elsevier 
A nanocomposite matrix composed of 4-6 nm ZnO NPs uniformly embedded in rGO sheets enabled efficient charge transfer. At an optimum $\mathrm{pH}$ of 6.9 and a tyrosinase loading capacity of $200 \mathrm{U}$, the assay displayed a wide dynamic range of $0.1-1500 \mathrm{pM}$ with a high sensitivity $(39.56 \pm 0.41 \mu \mathrm{A} / \mathrm{nM})$ and a LOD as low as $8.75 \pm 0.64 \mathrm{pM}$ [128]. Figure $9 \mathrm{~b}$ explains the fabrication and working of Tyr/ZnO-rGO/ITO biosensing platform are.

Carbon nanofibers (CNFs) are one-dimensional nanomaterials with large active surface areas. Electron transport is accelerated in only one direction by reducing the diameter of the CNFs, which improves conductivity and shortens the detection time of the biosensor [129]. Li et al. developed an anionic surfactant-assisted equilibrium adsorption method and electrospinning method to fabricate highly dispersed $\mathrm{Ni} / \mathrm{CoO}$-loaded carbon nanofibers to quantitatively detect glucose. Compared with bare GCE, Ni-CoO/CNF electrodes have a larger resistance [130]. Sun et al. prepared a $\mathrm{MgO}$-decorated carbon nanofiber (MgO@CNFs) nanocomposite and an $\mathrm{Hb}$-modified carbon ionic liquid electrode for detecting the electrocatalytic activity of trichloroacetic acid. $\mathrm{MgO} @ \mathrm{CNF}$ nanocomposites have been found to play an important role in increasing the electron transport rate, providing better electron transport channels with synergistic functions with highly conductive networks in electrochemical processes [131].

\subsection{Wearable electrochemical sensors}

Recently, wearable sensing technology has been rapidly adopted by a variety of traditional consumers and manufacturers of medical products. The explosive growth of wearable sensors is fueled by the economics and ergonomics of advances in small electronic devices, the proliferation of smartphones and connected devices, the growing consumer desire for health awareness, and the desire for doctors to constantly obtain quality medical data from their patients [132]. The source of secretions, the exocrine glands, are distributed throughout the body, especially under the hands, feet, waist, and arms (Fig. 10a) [133]. Sweat is an easy-to-collect biological fluid and has been used in the assessment of several diseases, including cystic fibrosis, as the demand for health monitoring devices has increased. Therefore, it is attracting attention as a source of information on hydration status and drugs. In recent years, sweat has been used to detect disease markers, such as sodium, potassium, calcium, phosphate, and glucose [134]. Figure 10b shows examples of biosensors for (a)

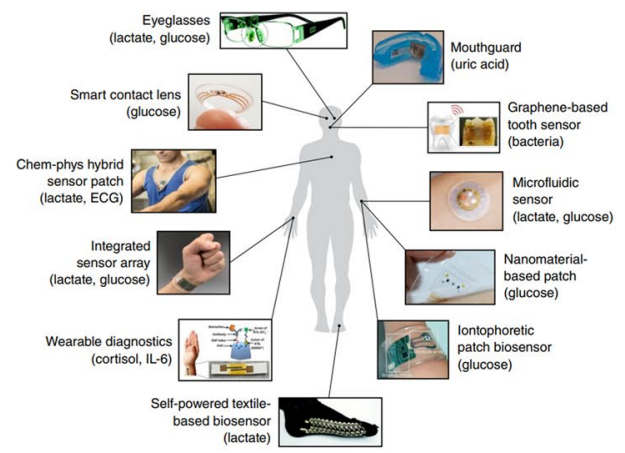

(b)

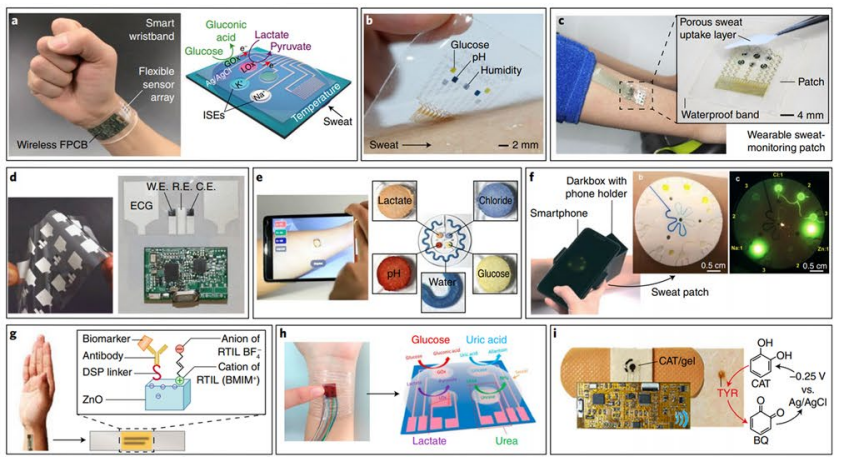

Fig. 10 a Representative examples of wearable biosensors. Reproduced with permission from Ref. [134]. Copyright (2019) Springer. b Representative of epidermal biosensors for real-time monitoring of sweat. Reproduced with permission from Ref. [134]. Copyright (2019) Springer. c Schematic representation of microneedle sensor for L-Dopa detection and portable wireless electroanalyzer enabled (c)

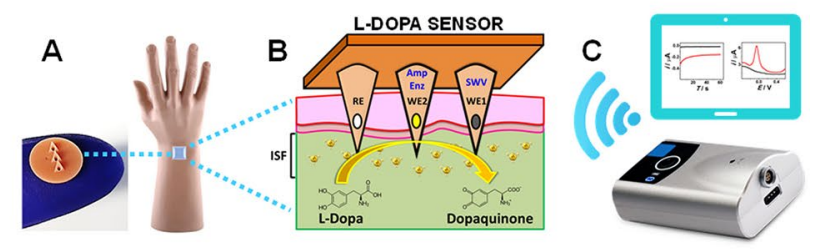

(d)

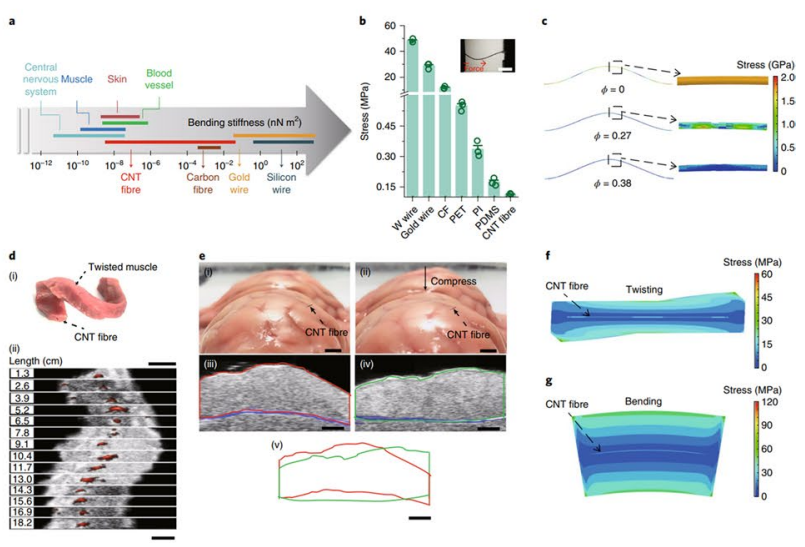

with wireless data transmission to the smart device. Reproduced with permission from Ref. [140]. Copyright (2019) ACS. d Mechanical match, biocompatibility and biointegration of the implanted CNT fiber. Reproduced with permission from Ref. [144]. Copyright (2020) Springer 
real- time monitoring of sweat. Sweat glucose levels are $0.06-0.11 \mathrm{mmol} / \mathrm{L}$ in healthy subjects and $0.01-1 \mathrm{mmol} / \mathrm{L}$ in diabetics [135]. Lee et al. reported a novel material structure, device design, and system integration strategy for a sweat glucose monitoring device integrated with feedback transdermal drug delivery microneedles with wearable-patch type or disposable-strip type. For efficient sweat control and sensing, the sweat monitoring patch is assembled with multiple sweat-uptake and waterproof layers, and sensor sizes are miniaturized to the point that approximately $1 \mu \mathrm{L}$ of sweat is sufficient for reliable measurement reported in $\mathrm{mmol} / \mathrm{L}$. Wearable devices that measure the concentration of sweat glucose in various forms have also been reported [136] Lee et al. developed a microneedle patch for sweat-based diabetes that detects $\mathrm{H}_{2} \mathrm{O}_{2}$ generated from a glucose oxidase patch and can be thermally actuated to deliver metformin and reduce blood glucose levels [137].

Another biological fluid that can be used to monitor glucose conditions is the saliva. In patients with diabetes, changes in hormonal and nervous balance can affect the salivary glands, which act as blood sugar filters in the blood and increase salivary glucose secretion [138]. Arakawa et al. developed a mouthguard biosensor for the non-invasive monitoring of saliva glucose. The mouthguard biosensor was able to perform real-time continuous wireless measurements of $0.05-1.0 \mathrm{mmol} / \mathrm{L}$ glucose in artificial saliva using a virtual jaw. Since the concentration of many important biomarkers in saliva is much lower than that in blood, extremely sensitive sensors are required for accurate monitoring. Compared to other non-invasively sampled biofluids, saliva is easily sampled without complex procedures but consists of a rich matrix of constituents that can be easily contaminated by external factors [139]. Wang et al. developed a new orthogonal electrochemical/biocatalytic microneedle sensor array strategy for continuous minimally invasive monitoring of levodopa (L-Dopa), the most effective medication for treating PD (Fig. 10c) [140]. Recently, Wang et al. presented an integrated device that provides mechanical resilience and flexibility while conforming to curved skin surfaces and reliably detects glucose in interstitial fluid and lactic acid, caffeine, and alcohol in sweat without crosstalk between individual sensors. Continuous, simultaneous acoustic and electrochemical sensing via integrated wearable devices can enrich our understanding of the body's response to daily activities and help predict abnormal physiological changes early [141]. Rogers et al. developed a battery-free, skininterfaced microfluidic/electronic system for simultaneous electrochemical, colorimetric, and volumetric analyses of sweat. The wireless interface enabled both battery-free operation and the robust acquisition of digital data generated by biofuel cell-based electrochemical sensors. Field studies and correlation of data acquired by glucose and lactate sweat sensors with blood levels demonstrate both the ability for long-term use and the potential for noninvasive tracking of blood analyte concentrations [142].

Continuous health monitoring is a promising alternative to current therapeutic health monitoring strategies and has a strong potential to improve personalized treatment. Given continued efforts to miniaturize electronic devices, in vivo sensors are likely to evolve to full capacity as implantable sensors in the coming years [143]. Sun et al. developed a flexible fibre-based implantable electrochemical sensor that mimics the hierarchical and helical assembly of native soft tissues. CNTs twisted into hierarchical and helical bundles of fibers resemble muscle filaments, match the bending stiffness of tissues and cells, and provide a flexible, strong, and stable fiber-tissue interface. The implantable fibers showed good biocompatibility and were further modified for in vivo applications. The sensor showed real-time monitoring of $\mathrm{H}_{2} \mathrm{O}_{2}$ in solid tumors and $\mathrm{Ca}^{2+}$ and glucose concentrations in blood vessels. Integrating the sensing fiber with a wireless transmission device enables portable and convenient monitoring of physiological information [144]. Figure 10d demonstrates mechanical match, biocompatibility and biointegration of the implanted CNT fiber. Sheng et al. developed a wireless thin-film-based implantable microprobe system for optogenetic stimulation and electrochemical sensing of dopamine in the brain of animals. Tiny vertically stacked micro-LEDs, diamond, and PEDOT: PSS films are combined to realize optogenetic stimulation and dopamine sensing in a minimally invasive platform. The unique electrical, optical, and thermal properties of the PEDOT: PSS-coated diamond film make this device suitable for highly sensitive electrochemical sensing without affecting micro-LED operation [145].

\section{Conclusions}

Along with the creation of a healthier society, consumers are increasingly demanding the development of sensors with low costs, good portability, energy efficiency, ease of use and manufacturing methods, and excellent sensing performance. To this end, extensive efforts are being made through complex interdisciplinary research in the fields of chemistry, materials science, physics, life sciences, and pharmaceutical medicine. Electrochemical sensors represent a crucial analytical tool for the sensitive, rapid, and selective determination of biological analytes. Unlike spectroscopic and chromatographic instruments, electrochemical sensors can be easily adapted for detecting a wide range of analytes while remaining inexpensive. Additionally, these sensors can be incorporated into robust, portable, or miniaturized devices, enabling their tailoring for specific applications. 
kIn this review, we summarized the current state of electrochemical biosensors used for the diagnosis of disease, including diabetes mellitus, neurodegenerative diseases, cancer, and coronaviruses, as well as the improvement of electrochemical biosensor detection performance using DNA, enzymes, nanoparticles, and carbon materials. Electrochemical biosensors are attracting attention due to their sensitivity, rapid analysis, and cost-effectiveness, whose choice of biomarkers and materials can facilitate the detection of many diseases. Thus, detection using electrochemical biosensors holds great potential for applications in complex diseases.

Acknowledgements This work was supported by the National Research Foundation of Korea (NRF, Grant No. NRF-2021R1A2C2004760, NRF-2020R1C1C1008641) and the Korea Health Industry Development Institute (KHIDI, Grant No. HU21C0053).

\section{Declaration}

Conflict of interest The authors declare that they have no conflict of interest.

Ethical statement The authors declare that they have no known competing financial interests.

\section{References}

1. Lee TM. Over-the-counter biosensors: past, present, and future. Sensors. 2008;8(9):5535-59.

2. Marrugo-Ramírez J, Mir M, Samitier J. Blood-based cancer biomarkers in liquid biopsy: a promising non-invasive alternative to tissue biopsy. Int J Mol Sci. 2018;19(10):2877.

3. Ronkainen NJ, Halsall HB, Heineman WR. Electrochemical biosensors. Chem Soc Rev. 2010;39(5):1747-63.

4. Wang J. Electrochemical biosensors: towards point-of-care cancer diagnostics. Biosens Bioelectron. 2006;21(10):1887-92.

5. Shrivastav AM, Cvelbar U, Abdulhalim I. A comprehensive review on plasmonic-based biosensors used in viral diagnostics. Commun Biol. 2021;4(1):70.

6. Mehrotra P. Biosensors and their applications - a review. J Oral Biol Craniofac Res. 2016;6(2):153-9.

7. Ausó E, Gómez-Vicente V, Esquiva G. Biomarkers for Alzheimer's disease early diagnosis. J Pers Med. 2020;10(3):114.

8. Reddy KK, Bandal H, Satyanarayana M, Goud KY, Gobi KV, Jayaramudu T, Amalraj J, Kim H. Recent trends in electrochemical sensors for vital biomedical markers using hybrid nanostructured materials. Adv Sci. 2020;7(13):1902980.

9. Grieshaber D, MacKenzie R, Vörös J, Reimhult E. Electrochemical biosensors - sensor principles and architectures. Sensors. 2008;8(3):1400-58.

10. Naresh V, Lee N. A review on biosensors and recent development of nanostructured materials-enabled biosensors. Sensors. 2021;21(4):1109.

11. Hammond JL, Formisano N, Estrela P, Carrara S, Tkac J. Electrochemical biosensors and nanobiosensors. Essays Biochem. 2016;60(1):69-80.

12. Chen M, Wu D, Tu S, Yang C, Chen DJ, and Xu Y. CRISPR/Cas9 cleavage triggered ESDR for circulating tumor DNA detection based on a 3D graphene/AuPtPd nanoflower biosensor. Biosens Bioelectron. 2021;173:112821.
13. Kim JH, Hong SG, Wee Y, Hu S, Kwon Y, Ha S, Kim J. Enzyme precipitate coating of pyranose oxidase on carbon nanotubes and their electrochemical applications. Biosens Bioelectron. 2017;87:365-72.

14. Chowdhury AD, Takemura K, Li TC, Suzuki T, Park EY. Electrical pulse-induced electrochemical biosensor for hepatitis $\mathrm{E}$ virus detection. Nat Commun. 2019;10(1):3737.

15. Chen M, Wu D, Tu S, Yang C, Chen D, Xu Y. A novel biosensor for the ultrasensitive detection of the lncRNA biomarker MALAT1 in non-small cell lung cancer. Sci Rep. 2021;11(1):3666.

16. Patel S, Nanda R, Sahoo S, Mohapatra E. Biosensors in health care: the milestones achieved in their development towards lab-on-chip-analysis. Biochem Res Int. 2016;2016:3130469.

17. Yoo EH, Lee SY. Glucose biosensors: an overview of use in clinical practice. Sensors (Basel). 2010;10(5):4558-76.

18. Teymourian H, Barfidokht A, Wang J. Electrochemical glucose sensors in diabetes management: an updated review (2010 2020). Chem Soc Rev. 2020;49(21):7671-709.

19. Chia HL, Sturala J, Webster RD, Pumera M. Functionalized 2D Germanene and silicene enzymatic system. Adv Funct Mater. 2021;31(16):2011125.

20. Ojeda I, Barrejón M, Arellano LM, González-Cortés A, YáñezSedeño P, Langa F, Pingarrón JM. Grafted-double walled carbon nanotubes as electrochemical platforms for immobilization of antibodies using a metallic-complex chelating polymer: application to the determination of Adiponectin Cytokine in Serum. Biosens Bioelectron. 2015;74:24-9.

21. Lenters-Westra E, Schindhelm RK, Bilo HJ, Slingerland RJ. Haemoglobin A1c: historical overview and current concepts. Diabetes Res Clin Pract. 2012;99(2):75-84.

22. Pundir CS, Chawla S. Determination of glycated hemoglobin with special emphasis on biosensing methods. Anal Biochem. 2014;444:47-56.

23. Kim DM, Shim YB. Disposable amperometric glycated hemoglobin sensor for the finger prick blood test. Anal Chem. 2014;85(13):6536-43.

24. Wang X, Su J, Zeng D, Liu G, Liu L, Xu Y, Wang C, Liu X, Wang L, Mi X. Gold nano-flowers (Au NFs) modified screenprinted carbon electrode electrochemical biosensor for labelfree and quantitative detection of glycated hemoglobin. Talanta. 2019;201:119-25.

25. Gitler AD, Dhillon P, Shorter J. Neurodegenerative disease: models, mechanisms, and a new hope. Dis Model Mech. 2017;10(5):499-502.

26. Cicero CE, Mostile G, Vasta R, Rapisarda V, Signorelli SS, Ferrante M, Zappia M, Nicoletti A. Metals and neurodegenerative diseases. A Syst Rev Environ Res. 2017;159:82-94.

27. Song Z, Zhou Y, Han X, Qin J, Tang X. Recent advances in enzymeless-based electrochemical sensors to diagnose neurodegenerative diseases. J Mater Chem B. 2021;9(5):1175-88.

28. Duan Y, Chen J, Jin Y, Tu Q, Wang S, Xiang J. Antibody-free determinations of low-mass, soluble oligomers of A $\beta 42$ and A $\beta 40$ by planar bilayer lipid membrane-based electrochemical biosensor. Anal Chem. 2021;93(7):3611-7.

29. Lee SJC, Nam E, Lee HJ, Savelieff MG, Lim MH. Towards an understanding of amyloid- $\beta$ oligomers: characterization, toxicity mechanisms, and inhibitors. Chem Soc Rev. 2017;46(2):310-23.

30. Shoji M, Kanai M. Cerebrospinal fluid $A \beta 40$ and $A \beta 42$ : natural course and clinical usefulness. J Alzheimers Dis. 2001;3(3):313-21.

31. Yu Y, Zhang L, Li C, Sun X, Tang D, Shi G. A method for evaluating the level of soluble $\beta$-amyloid (1-40/1-42) in Alzheimer's disease based on the binding of gelsolin to $\beta$-amyloid peptides. Angew Chem Int Ed Engl. 2014;53(47):12832-5. 
32. Qin J, Kim S, Cho M, Lee Y. Hierarchical and ultra-sensitive amyloid beta oligomer sensor for practical applications. Chem Eng J. 2020;401:126055.

33. Verwilst P, Kim HS, Kim S, Kang C, Kim JS. Shedding light on tau protein aggregation: the progress in developing highly selective fluorophores. Chem Soc Rev. 2018;47(7):2249-65.

34. Olsson B, Lautner R, Andreasson U, Öhrfelt A, Portelius E, Bjerke M, Hölttä M, Rosén C, Olsson C, Strobel G, Wu E, Dakin K, Petzold M, Blennow K, Zetterberg H. CSF and blood biomarkers for the diagnosis of Alzheimer's disease: a systematic review and meta-analysis. Lancet Neurol. 2016;15(7):673-84.

35. Kim K, Park CB. Femtomolar sensing of Alzheimer's tau proteins by water oxidation-coupled photoelectrochemical platform. Biosens Bioelectron. 2020;154(11):112075.

36. Zhang C, Liu Z, Zhang L, Zhu A, Liao F, Wan J, Zhou J, Tian Y. A robust $\mathrm{Au}-\mathrm{C} \equiv \mathrm{C}$ functionalized surface: toward real-time mapping and accurate quantification of $\mathrm{Fe} 2$ in the brains of live $\mathrm{AD}$ mouse models. Angew Chem Int Ed. 2020;59(16):20499-507.

37. Ganesh HVS, Chow AM, Kerman K. Recent advances in biosensors for neurodegenerative disease detection. Trends Analyt Chem. 2016;79:363-70.

38. Xu Q, Cheng H, Lehr J, Patil AV, Davis JJ. Graphene oxide interfaces in serum based autoantibody quantification. Anal Chem. 2015;87(1):346-50.

39. Ali SR, Ma Y, Parajuli RR, Balogun Y, He H. A Nonoxidative Sensor Based on a Self-Doped Polyaniline/Carbon Nanotube Composite for Sensitive and Selective Detection of the Neurotransmitter Dopamine. Anal Chem. 2007;79(6):2583-7.

40. Chang Y, Chen Y, Shao Y, Li B, Wu Y, Zhang W, Zhou Y, Yu Z, Lu L, Wang X, Guo G. Solid-phase microextraction integrated nanobiosensors for the serial detection of cytoplasmic dopamine in a single living cell. Biosens Bioelectron. 2021;175:112915.

41. Aziz A, Asif M, Azeem M, Ashraf G, Wang Z, Xiao F, Liu H. Self-stacking of exfoliated charged nanosheets of LDHs and graphene as biosensor with real-time tracking of dopamine from live cells. Anal Chim Acta. 2019;1047:197-207.

42. Bai J, Jiang X. A facile one-pot synthesis of copper sulfidedecorated reduced graphene oxide composites for enhanced detecting of $\mathrm{H} 2 \mathrm{O} 2$ in biological environments. Anal Chem. 2013;85(17):8095-101.

43. Wang L, Zhang Y, Cheng C, Liu X, Jiang H, Wang X. Highly sensitive electrochemical biosensor for evaluation of oxidative stress based on the nanointerface of graphene nanocomposites blended with gold, $\mathrm{Fe}_{3} \mathrm{O}_{4}$, and platinum nanoparticles. ACS Appl Mater Interfaces. 2015;7(33):18441-9.

44. Dong H, Zhou Y, Hao Y, Zhao L, Sun S, Zhang Y, Ye B, Xu M. "Turn-on" ratiometric electrochemical detection of $\mathrm{H} 2 \mathrm{O} 2$ in one drop of whole blood sample via a novel microelectrode sensor. Biosens Bioelectron. 2020;165:1102.

45. Ottervald J, Franzén B, Nilsson K, Andersson LI, Khademi M, Eriksson B, Kjellström S, Marko-Varga G, Végvári A, Harris RA, Laurell T, Miliotis T, Matusevicius D, Salter H, Ferm M, Olsson T. Multiple sclerosis: identification and clinical evaluation of novel CSF biomarkers. J Proteomics. 2010;73(6):1117-32.

46. Reindl M, Linington C, Brehm U, Egg R, DIlitz E, Deisenhammer F, Poewe W, Berger T, . Antibodies against the myelin oligodendrocyte glycoprotein and the myelin basic protein in multiple sclerosis and other neurological diseases: a comparative study. Brain. 1999;122(11):2047-56.

47. Derkus B, Emregul E, Yucesan C, Emregul KC. Myelin basic protein immunosensor for multiple sclerosis detection based upon label-free electrochemical impedance spectroscopy. Biosens Bioelectron. 2013;46:53-60.

48. Peer D, Karp JM, Hong S, Farokhzad OC, Margalit R, Langer R. Nanocarriers as an emerging platform for cancer therapy. Nat Nanotechnol. 2007;2(12):751-60.
49. Wardle J, Robb K, Vernon S, Waller J. Screening for prevention and early diagnosis of cancer. Am Psychol. 2015;70(2):119-33.

50. Sung H, Ferlay J, Siegel RL, Laversanne M, Soerjomataram I, Jemal A, Bray F. Global Cancer Statistics 2020: GLOBOCAN estimates of incidence and mortality worldwide for 36 cancers in 185 countries. CA Cancer J Clin. 2021;71(3):209-49.

51. Shen Q, Rahn JJ, Zhang J, Gunasekera N, Sun X, Shaw AR, Hendzel MJ, Hoffman P, Bernier A, Hugh JC. MUC1 initiates Src-CrkL-Rac1/Cdc42-mediated actin cytoskeletal protrusive motility after ligating intercellular adhesion molecule-1. Mol Cancer Res. 2008;6(4):555-67.

52. Jezersek B, Cervek J, Rudolf Z, Novaković S. Clinical evaluation of potential usefulness of CEA, CA 15-3, and MCA in follow-up of breast cancer patients. Cancer Lett. 1996;110(1-2):137-44.

53. Li T, Fan Q, Liu T, Zhu X, Zhao J, Li G. Detection of breast cancer cells specially and accurately by an electrochemical method. Biosens Bioelectron. 2010;25(12):2686-9.

54. Colomer R, Aranda-López I, Albanell J, García-Caballero T, Ciruelos E, López-García MÁ, Cortés J, Rojo F, Martín M, Palacios-Calvo J. Biomarkers in breast cancer: a consensus statement by the Spanish Society of Medical Oncology and the Spanish Society of Pathology. Clin Transl Oncol. 2018;20(7):815-26.

55. Rauf S, Lahcen AA, Aljedaibi A, Beduk T, de Oliveira Filho IJ, Salama KN. Gold nanostructured laser-scribed graphene: A new electrochemical biosensing platform for potential pointof-care testing of disease biomarkers. Biosens Bioelectron. 2021;180:1116.

56. Qi W, Li X, Kang J. Advances in the study of serum tumor markers of lung cancer. J Cancer Res Ther. 2014;10(Suppl):C95-101.

57. Aydin EB, Aydin M, Sezginturk MK. Selective and ultrasensitive electrochemical immunosensing of NSE cancer biomarker in human serum using epoxy-substituted poly(pyrrole) polymer modified disposable ITO electrode. Sens Actuators B Chem. 2020;306:127613.

58. Yang G, Xiao Z, Tang C, Deng Y, Huang H, He Z. Recent advances in biosensor for detection of lung cancer biomarkers. Biosens Bioelectron. 2019;141:111416.

59. Wang H, Rong Q, Ma Z. Polyhydroquinone-graphene composite as new redox species for sensitive electrochemical detection of cytokeratins antigen 21-1. Sci Rep. 2016;6:30623.

60. Yang H, Bao J, Huo D, Zeng Y, Wang X, Samalo M, Zhao J, Zhang S, Shen C, Hou C. Au doped poly-thionine and poly-mCresol purple: synthesis and their application in simultaneously electrochemical detection of two lung cancer markers CEA and CYFRA21-1. Talanta. 2021;224:1216.

61. Castle JC, Loewer M, Boegel S, de Graaf J, Bender C, Tadmor $\mathrm{AD}$, Boisguerin V, Bukur T, Sorn P, Paret C, Diken M, Kreiter $\mathrm{S}$, Türeci Ö, Sahin U. Immunomic, genomic and transcriptomic characterization of CT26 colorectal carcinoma. BMC Genom. 2014;15(1): 190 .

62. Hashkavayi AB, Raoof JB, Ojani R, Kavoosian S. Ultrasensitive electrochemical aptasensor based on sandwich architecture for selective label-free detection of colorectal cancer (CT26) cells. Biosens Bioelectron. 2017;92:630-7.

63. Duan F, Hu M, Guo C, Song Y, Wang M, He L, Zhang Z, Pettinari R, Zhou L. Chromium-based Metal-organic Framework Embedded with Cobalt Phthalocyanine for the Sensitively Impedimetric Cytosensing of Colorectal Cancer (CT26) Cells and Cell Imaging. Chem Eng J. 2020;398:125452.

64. Cheshomi H, Matin MM. Exosomes and their importance in metastasis, diagnosis, and therapy of colorectal cancer. J Cell Biochem. 2019;120:2671-86.

65. Wang M, Pan Y, Wu S, Sun Z, Wang L, Yang J, Yin Y, Li G. Detection of colorectal cancer-derived exosomes based on covalent organic frameworks. Biosens Bioelectron. 2020;169:112638. 
66. Tirnitz-Parker JEE. Hepatocellular carcinoma. Codon Publications; 2019.

67. Bialecki ES, Di Bisceglie AM. Diagnosis of hepatocellular carcinoma. HPB. 2005;7(1):26-34.

68. Ding C, Zhao F, Ren R, Lin JM. An electrochemical biosensor for alpha-fetoprotein based on carbon paste electrode constructed of room temperature ionic liquid and gold nanoparticles. Talanta. 2009;78(3):1148-54.

69. Cao J, Ouyang P, Yu S, Shi F, Ren C, Wang C, Shen M, Yang $\mathrm{Z}$. Hedgehog-like $\mathrm{Bi}_{2} \mathrm{~S}_{3}$ nanostructures: a novel composite soft template route to the synthesis and sensitive electrochemical immunoassay of the liver cancer biomarker. Chem Commun (Camb). 2021;57(14):1766-9.

70. Singh S, Gill AAS, Nlooto M, Karpoormath R. Prostate cancer biomarkers detection using nanoparticles based electrochemical biosensors. Biosens Bioelectron. 2019;137:213-21.

71. Pan LH, Kuo SH, Lin TY, Lin CW, Fang PY, Yang HW. An electrochemical biosensor to simultaneously detect VEGF and PSA for early prostate cancer diagnosis based on graphene oxide/ssDNA/PLLA nanoparticles. Biosens Bioelectron. 2017;89(1):598-605.

72. Gaspar MJ, Arribas I, Coca MC, Díez-Alonso M. Prognostic value of carcinoembryonic antigen, CA 19-9 and CA 72-4 in gastric carcinoma. Tumour Biol. 2001;22(5):318-22.

73. Wu D, Guo Z, Liu Y, Guo A, Lou W, Fan D, Wei Q. Sandwich-type electrochemical immunosensor using dumbbell-like nanoparticles for the determination of gastric cancer biomarker CA72-4. Talanta. 2015;134:305-9.

74. Fan H, Guo Z, Gao L, Zhang Y, Fan D, Ji G, Du B, Wei Q. Ultrasensitive electrochemical immunosensor for carbohydrate antigen $72-4$ based on dual signal amplification strategy of nanoporous gold and polyaniline-Au asymmetric multicomponent nanoparticles. Biosens Bioelectron. 2015;64:51-6.

75. Mohapatra S, Patra D, Satpathy S. An ensemble classifier system for early diagnosis of acute lymphoblastic leukemia in blood microscopic images. Neural Comput Appl. 2014;24(7):1887-904.

76. Khoshroo A, Hosseinzadeh L, Adib K, Rahimi-Nasrabadi M, Ahmadi F. Earlier diagnoses of acute leukemia by a sandwich type of electrochemical aptasensor based on copper sulfidegraphene composite. Anal Chim Acta. 2021;1146:1-10.

77. Hu B, Guo H, Zhou P, Shi ZL. Characteristics of SARS-CoV-2 and COVID-19. Nat Rev Microbiol. 2021;19(3):141-54.

78. Morales-Narváez E, Dincer C. The impact of biosensing in a pandemic outbreak: COVID-19. Biosens Bioelectron. 2020;163:112274.

79. Yakoh A, Pimpitak U, Rengpipat S, Hirankarn N, Chailapakul O, Chaiyo S. Paper-based electrochemical biosensor for diagnosing COVID-19: Detection of SARS-CoV-2 antibodies and antigen. Biosens Bioelectron. 2021;176:112912.

80. Chaibun T, Puenpa J, Ngamdee T, Boonapatcharoen N, Athamanolap P, O'Mullane AP, Vongpunsawad S, Poovorawan Y, Lee SY, Lertanantawong B. Rapid electrochemical detection of coronavirus SARS-CoV-2. Nat Commun. 2021;12(1):802.

81. Cady NC, Tokranova N, Minor A, Nikvand N, Strle K, Lee WT, Page W, Guignon E, Pilar A, Gibson GN. Multiplexed detection and quantification of human antibody response to COVID-19 infection using a plasmon enhanced biosensor platform. Biosens Bioelectron. 2021;171:112679.

82. Zhang C, Du X. Electrochemical sensors based on carbon nanomaterial used in diagnosing metabolic disease. Front Chem. 2020;8:651.

83. Bandodkar AJ, Wang J. Non-invasive wearable electrochemical sensors: a review. Trends Biotechnol. 2014;32(7):363-71.
84. Ansari SA, Husain Q. Potential applications of enzymes immobilized on/in nano materials: a review. Biotechnol Adv. 2012;30(3):512-23.

85. Luo X, Morrin A, Killard AJ, Smyth MR. Application of nanoparticles in electrochemical sensors and biosensors. Electroanalysis. 2006;18(4):319-26.

86. Kim JH, Hong SG, Sun HJ, Ha S, Kim J. Precipitated and chemically-crosslinked laccase over polyaniline nanofiber for high performance phenol sensing. Chemosphere. 2016;143:142-7.

87. Liu Y, Liu Y, Qiao L, Liu Y, Liu B. Advances in signal amplification strategies for electrochemical biosensing. Curr Opin Electrochem. 2018;12:5-12.

88. Roh S, Chung T, Lee B. Overview of the characteristics of microand nano-structured surface plasmon resonance sensors. Sensors. 2011;11(2):1565-88.

89. Diculescu VC, Chiorcea-Paquim A, Oliveira-Brett A. Applications of a DNA-electrochemical Biosensor. Trac-Trend Anal Chem (Regular Ed). 2016;79:23-36.

90. Majumdar S, Thakur D, Chowdhury D. DNA carbon-nanodots based electrochemical biosensor for detection of mutagenic nitrosamines. ACS Appl Bio Mater. 2020;3(3):1796-803.

91. Forterre A, Komuro H, Aminova S, Harada M. A Comprehensive review of cancer MicroRNA therapeutic delivery strategies. Cancers. 2020;12(7):1852.

92. Moccia M, Caratelli V, Cinti S, Pede B, Avitabile C, Saviano M, Imbriani AL, Moscone D, Arduini F. Paper-based electrochemical peptide nucleic acid (PNA) biosensor for detection of miRNA-492: a pancreatic ductal adenocarcinoma biomarker. Biosens Bioelectron. 2020;165:112371.

93. Masud MK, Na J, Lin TE, Malgras V, Preet A, Ibn Sina AA, Wood K, Billah M, Kim J, You J, Kani K, Whitten AE, Salomon C, Nguyen NT, Shiddiky MJA, Trau M, HossainMd SA, Yamauchi Y. Nanostructured mesoporous gold biosensor for microRNA detection at attomolar level. Biosens Bioelectron. 2020;168:1129.

94. Chen S-C, Chen K-T, Jou AF-J. Polydopamine-gold composite-based electrochemical biosensor using dual-amplification strategy for detecting pancreatic cancer-associated microRNA. Biosens Bioelectron. 2021;173:112815.

95. Zhou L, Wang T, Bai Y, Li Y, Qiu J, Yu W, Zhang S. Dual-amplified Strategy for Ultrasensitive Electrochemical Biosensor Based on Click Chemistry-mediated Enzyme-assisted Target Recycling and Functionalized Fullerene Nanoparticles in the Detection of MicroRNA-141. Biosens Bioelectron. 2020;150:1164.

96. Wang G, Huang Y, Wang LL, Zhang YF, Xu J, Zhou Y, Lourenco GF, Zhang B, Wang Y, Ren RJ, Halliday GM, Chen SD. MicroRNA-146a suppresses ROCK1 allowing hyperphosphorylation of tau in Alzheimer's disease. Sci Rep. 2016;6:26697.

97. Khalilzadeh B, Rashidi M, Soleimanian A, Tajalli H, Kanberoglu GS, Baradaran B, Rashidi MR. Development of a reliable microRNA based electrochemical genosensor for monitoring of miR-146a, as key regulatory agent of neurodegenerative disease. Int J Biol Macromol. 2019;134:695-703.

98. Lu J, Wang J, Hu X, Gyimah E, Yakubu S, Wang K, Wu X, Zhang Z. Electrochemical biosensor based on tetrahedral DNA nanostructures and G-Quadruplex-Hemin conformation for the ultrasensitive detection of MICRORNA-21 in Serum. Anal Chem. 2019;91(11):7353-9.

99. Li X, Li X, Li D, Zhao M, Wu H, Shen B, Liu P, Ding S. Electrochemical biosensor for ultrasensitive exosomal MiRNA analysis by cascade primer exchange reaction and MOF@Pt@MOF nanozyme. Biosens Bioelectron. 2020;168:112554.

100. Wu J, Lv W, Yang Q, Li H, Li F. Label-free homogeneous electrochemical detection of microRNA based on target-induced anti-shielding against the catalytic activity of two-dimension nanozyme. Biosens Bioelectron. 2021;171:112707. 
101. Keller L, Belloum Y, Wikman H, Pantel K. Clinical relevance of blood-based CtDNA analysis: mutation detection and beyond. $\mathrm{Br}$ J Cancer. 2020;124(2):345-58.

102. Chen K, Zhao H, Wang Z, Lan M. A novel signal amplification label based on AuPt alloy nanoparticles supported by high-active carbon for the electrochemical detection of circulating tumor DNA. Anal Chim Acta. 2021;1169:338628.

103. Campaña AL, Florez SL, Noguera MJ, Fuentes OP, Puentes PR, Cruz JC, Osma JF. Enzyme-based electrochemical biosensors for microfluidic platforms to detect pharmaceutical residues in wastewater. Biosensors. 2019;9(1):41.

104. Li X, Feng Q, Lu K, Huang J, Zhang Y, Hou Y, Qiao H, Li D, Wei Q. Encapsulating enzyme into metal-organic framework during in-situ growth on cellulose acetate nanofibers as self-powered glucose biosensor. Biosens Bioelectron. 2021;171:1190.

105. Yan Y, Qiao Z, Hai X, Song W, Bi S. Versatile electrochemical biosensor based on bi-enzyme cascade biocatalysis spatially regulated by DNA architecture. Biosens Bioelectron. 2021;174:112827.

106. Takeda K, Kusuoka R, Inukai M, Igarashi K, Ohno H, Nakamura $\mathrm{N}$. An amperometric biosensor of L-fucose in urine for the first screening test of cancer. Biosens Bioelectron. 2021;174:112831.

107. Chen $\mathrm{L}, \mathrm{Wu} \mathrm{J}$, Yan $\mathrm{F}, \mathrm{Ju} \mathrm{H}$. A facile strategy for quantitative sensing of glycans on cell surface using organic electrochemical transistors. Biosens Bioelectron. 2021;175:112878.

108. Hiraka K, Tsugawa W, Asano R, Yokus MA, Ikebukuro K, Daniele MA, Sode K. Rational design of direct electron transfer type 1-lactate dehydrogenase for the development of multiplexed biosensor. Biosens Bioelectron. 2021;176:112933.

109. Xia T, Liu G, Wang J, Hou S, Hou S. MXene-based enzymatic sensor for highly sensitive and selective detection of cholesterol. Biosens Bioelectron. 2021;183:113243.

110. Kucherenko IS, Soldatkin OO, Kucherenko DY, Soldatkina OV, Dzyadevych SV. Advances in nanomaterial application in enzymebased electrochemical biosensors: a review. Nanoscale Adv. 2019;1:4560-77.

111. Pingarrón JM, Yáñez-Sedeño P, González-Cortés A. Gold nanoparticle-based electrochemical biosensors. Electrochim Acta. 2008;53(19):5848-66.

112. Miao J, Du K, Li X, Xu X, Dong X, Fang J, Cao W, Wei Q. Ratiometric electrochemical immunosensor for the detection of procalcitonin based on the ratios of $\mathrm{SiO}_{2}-\mathrm{Fc}-\mathrm{COOH}-\mathrm{Au}$ and UiO66-TB complexes. Biosens Bioelectron. 2021;171:112713.

113. Du X, Zhang Z, Zheng X, Zhang H, Dong D, Zhang Z, Liu M, Zhou J. An electrochemical biosensor for the detection of epithelial-mesenchymal transition. Nat Commun. 2020;11(1):192.

114. Jiang L, Wang L, Zhan DS, Jiang WR, Fodjo EK, Hafez ME, Zhang YM, Zhao H, Qian RC, Li DW. Electrochemically renewable SERS sensor: A new platform for the detection of metabolites involved in peroxide production. Biosens Bioelectron. 2021;175:112918.

115. Xing Y, Feng XZ, Zhang L, Hou J, Han GC, Chen Z. A sensitive and selective electrochemical biosensor for the determination of beta-amyloid oligomer by inhibiting the peptide-triggered in situ assembly of silver nanoparticles. Int J Nanomed. 2017;12:3171-9.

116. Liu J, Siavash Moakhar R, Sudalaiyadum Perumal A, Roman HN, Mahshid S, Wachsmann-Hogiu S. An AgNP-deposited commercial electrochemistry test strip as a platform for urea detection. Sci Rep. 2020;10(1):9527.

117. Hou L, Huang Y, Hou W, Yan Y, Liu J, Xia N. Modificationfree amperometric biosensor for the detection of wild-type p53 protein based on the in-situ formation of silver nanoparticle networks for signal amplification. Int J Biol Macromol. 2020;158:580-6.
118. Tai MJY, Perumal V, Gopinath SCB, Raja PB, Ibrahim MNM, Jantan IN, Suhaimi NSH, Liu WW. Laser-scribed graphene nanofiber decorated with oil palm lignin capped silver nanoparticles: a green biosensor. Sci Rep. 2021;11(1):5475.

119. Nguyen TNH, Nolan JK, Park H, Lam S, Fattah M, Page JC, Joe HE, Jun MBG, Lee H, Kim SJ, Shi R, Lee H. Facile fabrication of flexible glutamate biosensor using direct writing of platinum nanoparticle-based nanocomposite ink. Biosens Bioelectron. 2019;131:257-66.

120. Wu H, Shi C, Zhu Q, Li Y, Xu Z, Wei C, Chen D, Huang X. Capillary-driven blood separation and in-situ electrochemical detection based on 3D conductive gradient hollow fiber membrane. Biosens Bioelectron. 2021;171:112722.

121. Ji X, Wang H, Song B, Chu B, He Y. Silicon nanomaterials for biosensing and bioimaging analysis. Front Chem. 2018;6:38.

122. Kholafazad Kordasht H, Pazhuhi M, Pashazadeh-Panahi P, Hasanzadeh M, Shadjou N. Multifunctional aptasensors based on mesoporous silica nanoparticles as an efficient platform for bioanalytical applications: recent advances. Trac-Trend Anal Chem. 2020;124:115778.

123. Liu Y-C, Hsu W-F, Wu T-M. Electrochemical determination of dopamine using a conductive polypyrrole/carbon-coated mesoporous silica composite electrode. J Appl Electrochem. 2020;50(3):311-9.

124. Cho IH, Kim DH, Park S. Electrochemical biosensors: perspective on functional nanomaterials for on-site analysis. Biomater Res. 2020;24:6.

125. Lee JY, Cho D, Cho S-P, Choi J-H, Sung SJ, Hong S, Yu W-R. Semiconducting carbon nanotube fibers for electrochemical biosensor platforms. Mater Des. 2020;192:1040.

126. Chapin AA, Rajasekaran PR, Quan DN, et al. Electrochemical measurement of serotonin by Au-CNT electrodes fabricated on microporous cell culture membranes. Microsyst Nanoeng. 2020;6:90.

127. Ortiz E, Gallay P, Galicia L, Eguílaz M, Rivas G. Nanoarchitectures based on multi-walled carbon nanotubes non-covalently functionalized with Concanavalin A: A new building-block with supramolecular recognition properties for the development of electrochemical biosensors. Sens Actuator B-Chem. 2019;292:254-62.

128. Verma S, Arya P, Singh A, Kaswan J, Shukla A, Kushwaha HR, Gupta S, Singh SP. ZnO-rGO nanocomposite based bioelectrode for sensitive and ultrafast detection of dopamine in human serum. Biosens Bioelectron. 2020;165:112347.

129. Sanati A, Jalali M, Raeissi K, Karimzadeh F, Kharaziha M, Mahshid SS, Mahshid S. A review on recent advancements in electrochemical biosensing using carbonaceous nanomaterials. Mikrochim Acta. 2019;186(12):773.

130. Mei Q, Fu R, Ding Y, Li Li, Wang A, Duan D, Ye D. Electrospinning of highly dispersed $\mathrm{Ni} / \mathrm{CoO}$ carbon nanofiber and its application in glucose electrochemical sensor. J Electroanal Chem. 2019;847:1175.

131. Yones HA, Zhu L, Shao B, Zhang S, Xie H, Li X, Sun W. Magnesium oxide/carbon nanofiber nanocomposite modified electrode for electrochemical hemoglobin sensor. Int J Electrochem Sci. 2021;16:210225.

132. Heikenfeld J, Jajack A, Rogers J, Gutruf P, Tian L, Pan T, Li R, Khine M, Kim J, Wang J, Kim J. Wearable sensors: modalities, challenges, and prospects. Lab Chip. 2018;18(2):217-48.

133. Corrie SR, Coffey JW, Islam J, Markey KA, Kendall MA. Blood, sweat, and tears: developing clinically relevant protein biosensors for integrated body fluid analysis. Analyst. 2015;140(13):4350-64.

134. Kim J, Campbell AS, de Ávila BE, Wang J. Wearable biosensors for healthcare monitoring. Nat Biotechnol. 2019;37(4):389-406. 
135. Bruen D, Delaney C, Florea L, Diamond D. Glucose Sensing for Diabetes Monitoring: Recent Developments. Sensors. 2017;17(8): 1866.

136. Lee H, Song C, Hong YS, Kim MS, Cho HR, Kang T, Shin K, Choi SH, Hyeon T, Kim DH. Wearable/disposable sweat-based glucose monitoring device with multistage transdermal drug delivery module. Sci Adv. 2017; 3(3):e1601314.

137. Lee H, Choi TK, Lee YB, Cho HR, Ghaffari R, Wang L, Choi HJ, Chung TD, Lu N, Hyeon T, Choi SH, Kim DH. A graphenebased electrochemical device with thermoresponsive microneedles for diabetes monitoring and therapy. Nat Nanotechnol. 2016;11(6):566-72.

138. Viswanath B, Choi CS, Lee K, Kim S. Recent trends in the development of diagnostic tools for diabetes mellitus using patient saliva. Trac-Trend Anal Chem. 2017;89:60-7.

139. Arakawa T, Kuroki Y, Nitta H, Chouhan P, Toma K, Sawada S, Takeuchi S, Sekita T, Akiyoshi K, Minakuchi S, Mitsubayashi K. Mouthguard biosensor with telemetry system for monitoring of saliva glucose: A novel cavitas sensor. Biosens Bioelectron. 2016;84:106-11.

140. Goud KY, Moonla C, Mishra RK, Yu C, Narayan R, Litvan I, Wang J. Wearable Electrochemical Microneedle Sensor for Continuous Monitoring of Levodopa: Toward Parkinson Management. ACS Sens. 2019;4(8):2196-204.

141. Sempionatto JR, Lin M, Yin L, De la Paz E, Pei K, Sonsa-Ard T, de Loyola Silva AN, Khorshed AA, Zhang F, Tostado N, Xu $\mathrm{S}$, Wang J. An epidermal patch for the simultaneous monitoring of haemodynamic and metabolic biomarkers. Nat Biomed Eng. 2021;5:737-748.
142. Bandodkar AJ, Gutruf P, Choi J, Lee K, Sekine Y, Reeder JT, Jeang WJ, Aranyosi AJ, Lee SP, Model JB, Ghaffari R, Su CJ, Leshock JP, Ray T, Verrillo A, Thomas K, Krishnamurthi V, Han S, Kim J, Krishnan S, Hang T, Rogers JA. Battery-free, skin-interfaced microfluidic/electronic systems for simultaneous electrochemical, colorimetric, and volumetric analysis of sweat. Sci Adv. 2019;5(1): eaav3294.

143. Bian S, Zhu B, Rong G, Sawan M. Towards wearable and implantable continuous drug monitoring: A review. J Pharm Anal. 2021;11(1):1-14.

144. Wang L, Xie S, Wang Z, Liu F, Yang Y, Tang C, Wu X, Liu P, Li Y, Saiyin H, Zheng S, Sun X, Xu F, Yu H, Peng H. Functionalized helical fibre bundles of carbon nanotubes as electrochemical sensors for long-term in vivo monitoring of multiple disease biomarkers. Nat Biomed Eng. 2020;4(2):159-71.

145. Liu C, Zhao Y, Cai X, Xie Y, Wang T, Cheng D, Li L, Li R, Deng Y, Ding H, Lv G, Zhao G, Liu L, Zou G, Feng M, Sun Q, Yin L, Sheng X. A Wireless, Implantable Optoelectrochemical Probe for Optogenetic Stimulation and Dopamine Detection. Microsyst Nanoeng. 2020;6:64.

Publisher's Note Springer Nature remains neutral with regard to jurisdictional claims in published maps and institutional affiliations. 